UMR 5824

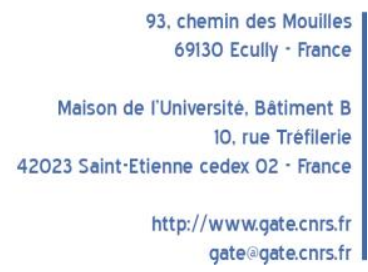

WP 2025 - August 2020, revised August 2021

\title{
Uncovering Illegal and Underground Economies: The Case of Mafia Extortion Racketeering
}

\author{
Lavinia Piemontese
}

\begin{abstract}
:
I propose a new approach for quantifying the economic cost of hidden economies. I apply this method to the case of mafia racketeering in Northern Italy, and in so doing, provide the first explicit estimate of the cost of mafia spread in this area. show that acts of extortion imposed on certain firms are linked to resource misallocation. I quantify the share of output that the mafia extorts from firms, which ranges between 0.5 and 5 percent of firm-level output for the taxed firms, this implies a loss between $0.6 \%$ and $8 \%$ of aggregate value added. Quite remarkably, only one-fourth of this cost consists of the aggregate transfer to the mafia, while the remaining share corresponds to the contraction of production due to misallocation. This result is robust to alternative specifications of my model.
\end{abstract}

\section{Keywords:}

Organized crime, Extortion Racketeering, Resource Misallocation, Welfare Loss, within-industry OP covariance

JEL codes:

D22, D24, D61, K42, 017

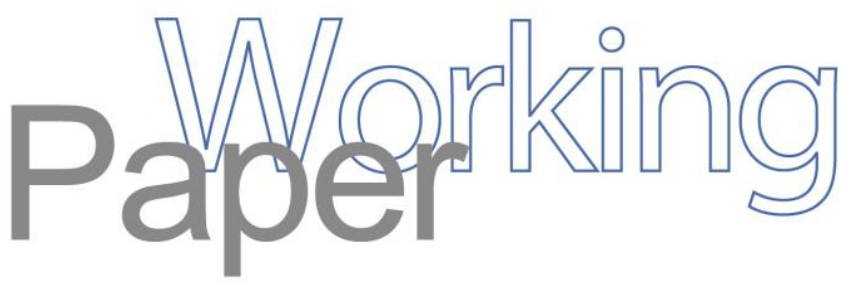




\title{
Uncovering Illegal and Underground Economies: The Case of Mafia Extortion Racketeering *
}

\author{
Author: Lavinia Piemontese ${ }^{\dagger}$
}

August 30, 2021

\begin{abstract}
I propose a new approach for quantifying the economic cost of hidden economies. I apply this method to the case of mafia racketeering in Northern Italy, and in so doing, provide the first explicit estimate of the cost of mafia spread in this area. show that acts of extortion imposed on certain firms are linked to resource misallocation. I quantify the share of output that the mafia extorts from firms, which ranges between 0.5 and 5 percent of firm-level output for the taxed firms, this implies a loss between $0.6 \%$ and $8 \%$ of aggregate value added. Quite remarkably, only one-fourth of this cost consists of the aggregate transfer to the mafia, while the remaining share corresponds to the contraction of production due to misallocation. This result is robust to alternative specifications of my model.
\end{abstract}

Keywords: Organized crime, Extortion Racketeering, Resource Misallocation, Welfare Loss, within-industry OP covariance

JEL Codes: D22 D24 D61 K42 O17

\footnotetext{
* I am grateful to Hannes Mueller for his indispensable guidance and constant support. I thank Joan Llull and the members of the applied economics research group at the Universitat Autonoma de Barcelona for long and productive discussions. I am further indebted to all the participants of the 2017 ENTER jamboree at UCL, ENTER exchange seminar at Stockholm School of Economics, GSE jamboree, LACEA annual meeting, and the Workshop on Organized Crime for their useful comments. A special thanks to Mathieu Couttenier, Gianmarco Daniele, Mario Lavezzi, Annalisa Loviglio, Geert Mesters, Paolo Pinotti for their valuable reflections, and to Lucia Rizzica who also provided me with key aggregate statistics on mafia infiltration. I acknowledge financial support from the IDEX LYON from the University of Lyon under grant ANR-16-IDEX-0005 (French National Research Agency, "Programme Investissements d'Avenir" ) and from the Spanish Ministry of Economy and Competitiveness through an FPI Grant at CSIC-IAE Barcelona. I acknowledge the logistic support from the Laboratory for Elementary Data Analysis (ADELE). All errors are mine.

†lavinia.piemontese@ens-lyon.fr Univ Lyon, ENS de Lyon, GATE UMR 5824, F-69342 Lyon, France
} 


\section{Introduction}

Addressing illegal and underground economies is a priority for many governments and international organizations. Yet, how these economies influence economic agentssuch as firms and consumers-and the magnitude of such effects are relatively unknown. In large part, this is due to the hidden intrinsic nature of such economies and the consequent general lack of data concerning both the agents behind them (i.e., perpetrators of illicit activities) and those that are impacted by their effects (i.e., their victims). There is a clear need to develop new methodologies able to surmount this challenge. One alternative is to explore the microeconomic mechanisms behind the relationship between underground economies and their aggregate effects, particularly as aggregate outcomes are often readily observable. I make a step in this direction and propose a new method that provides valuable insights into the costs of illegal economies.

I tackle the lack of data on illicit activities at the micro level using a "bottom-up" perspective. Specifically, I analyze how the unobservable idiosyncratic distortions introduced by illegal economies have aggregate observable effects. This allows me to summarize and identify these distortions by looking at aggregate outcomes. I use this methodology to study the economic effects of mafia racketeering (pizzo) of firms located in Northern Italy. ${ }^{1}$ In line with relevant literature on misallocation (Bartelsman et al., 2013; Hsieh and Klenow, 2009; Restuccia and Rogerson, 2008), I develop a model where I show that in a market with heterogeneous producers, firms' response to pizzo can have aggregate effects. This occurs because pizzo is an idiosyncratic distortion on firm-level output; making it a highly suitable application for linking micro aspects to macro effects.

In this context, I do not observe either which firms are coerced, nor the amount of pizzo. The only information related to mafia activity I rely on is the share of firms subject to extortion. The data, gathered from official national records, gives the annual total number of reports of extortion that occurred in each Northern Italian province between 1998

\footnotetext{
${ }^{1}$ The word pizzo, derived from Sicilian dialect, indicates extortion perpetrated by the mafia. In this paper, I do not distinguish between different types of mafia organizations, which in Italy belong to either Cosa Nostra, Camorra, 'Ndrangheta, or Sacra Corona Unita.
} 
and 2012. For the purposes of the analysis, this information, together with an index of resource misallocation measured using the within-industry covariance between size and productivity, are sufficient to estimate the cost of the Italian mafia. In particular, I argue that misallocation arises because only certain firms (i.e., those that are coerced) must shrink their production and thus end up being smaller than less productive firms, which have not been impacted by the mafia. Therefore, by knowing how many firms have been extorted, I can back out the amount pizzo from the extent of resource misallocation that occurs in the markets infiltrated by the mafia.

The novelty of my method is that it successfully combines a panel data analysis with structural econometric techniques. Specifically, my empirical strategy consists of two main stages. In the first stage, I employ aggregate information on firms' performance to estimate the parameters needed to simulate what the Northern Italian economy would be like without the mafia. I estimate these parameters using fixed effect regressions that use aggregate output as the dependent variable. In the second stage, I use these parameters together with the data on extortion racketeering in a structural model. I simulate an economy affected by the mafia and infer pizzo by matching my simulated index of resource misallocation (the within-industry covariance between size and productivity) to that observed in the data. The model developed here not only provides a way to estimate the amount of pizzo, but also a means of understanding and quantifying the welfare loss that occurs in the infiltrated markets. Such loss is due to the fact that firms must transfer resources that would otherwise have been used productively. My results suggest that the total cost suffered by the Northern Italian economy between 2000 and 2012 ranges between 0.6 and 8 percent of sectorial aggregate value added. Quite remarkably, only one-fourth of this loss is constituted by the transfer of pizzo to the mafia. The remaining three-fourths consists of the forgone production due to misallocation. This means that the extortion of pizzo implies an economic loss, in terms of contraction of output, that is three times higher than what the mafia actually collects.

To quantify the extent of resource misallocation, I use the within-industry covariance between size and productivity derived in the decomposition of industry-productivity, proposed by Olley and Pakes (1996) (OP covariance henceforth). In this decomposition, aggregate productivity is the sum of firms' productivity weighted by their size, and can 
be split into an unweighted firm-level average and a covariance term. The covariance term measures the extent to which more productive firms tend to be larger than less productive ones. I make use of Bartelsman et al. (2013) results showing that in markets with few or no distortions, i.e., with no misallocation, the distributions of firms' productivity and firms' size are highly correlated. However, the strength of this link is weakened if firms face idiosyncratic distortions that impact their scale of output, which in turn implies a decrease of the OP covariance.

Along these lines, I explain how idiosyncratic distortions introduced by pizzo racketeering can impact the OP covariance of the infiltrated markets. Specifically, I propose a simple static multi-sectorial model of heterogeneous producers in the spirit of Hsieh and Klenow (2009), in which firms differ in their level of permanent total factor productivity and choose employment to produce in a monopolistic competition environment, taking wages as given. The mafia impacts firms randomly, i.e. their targeting is orthogonal to any firm's individual characteristic. ${ }^{2}$ This distortion is idiosyncratic because some producers are not subject to extortion racketeering, while others are, and because I let different firms to be extorted different pizzo rates. A central prediction of the model is that in an environment without the mafia, the distribution of firms' productivity and that of their size are perfectly correlated. If instead the mafia infiltrates the market and coerces a randomly chosen group of firms, the strength of the link between the two distributions is weakened, meaning that the market is affected by resource misallocation. To provide a quantitative estimate of pizzo and its related welfare loss, I build a panel dataset that provides information on every Northern Italian province over the period 1998-2012. This dataset combines information on mafia activity in Northern Italy, i.e., the yearly number of reports of extortion for every northern province, and aggregate information on firms' characteristics and performance over several industries, includ-

\footnotetext{
${ }^{2}$ This assumption is supported by suggestive evidence that extortion racketeering in Northern Italy is not as deeply rooted as it is in Southern Italy (Confesercenti, 2012). Pizzo is modeled as a proportional tax on firm-level output, which varies with firm-level size (Balletta and Lavezzi, 2019). This might imply that the mafia does not have enough information to carry out a rational targeting. I relax this assumption in the second part of the paper, where I consider two alternative targeting rules in which the mafia coerces the least / most productive firms.
} 
ing the within-sector OP covariance of every observed year and province. Importantly, mafia infiltration in Northern Italy is a relatively recent phenomenon, which has been particularly acute in certain regions (Confesercenti, 2012), and within specific sectors of the economy (Transcrime, 2013). I accordingly develop a definition of mafia-infiltrated markets with a temporal, a spatial, and a sectorial dimension. The structure of my dataset, whose statistical unit is sector-province-year, allows me to define as mafiainfiltrated: (i) specific industries, (ii) located in given Northern Italian provinces, (iii) observed after a certain point in time. All the remaining sectors-provinces-years are considered as non-mafia markets. Thanks to this three-dimensional definition of mafiainfiltrated market and a set of identifying assumptions included in my theoretical model, I can use non-mafia markets as the best counterfactual of the infiltrated markets without mafia activity. This is a crucial aspect for my estimation strategy, as it allows me to control for any attribute of each mafia-infiltrated market that is unrelated to mafia activity, and estimate pizzo as the only determinant of resource misallocation, other things being equal.

In the empirical part of the paper, I begin by providing suggestive evidence of a significant correlation between mafia activity and resource misallocation. In particular, I provide evidence that the OP covariance of mafia-infiltrated markets decreases after the arrival of organized crime, compared to the remaining markets. I then bring my theoretical model to the data, developing a two-stage analysis. First, I estimate the parameters of the model that are unrelated to mafia with fixed effect regressions using data on non-mafia markets. These parameters allow me to control for any characteristic that is unrelated to mafia activity. Second, I apply the method of simulated moments (MSM) to quantify the magnitude of pizzo imposed in each mafia-infiltrated market, by minimizing the distance between the simulated OP covariance delivered by the model and that observed in the data. In this stage, I control for the fact that the mafia can infiltrate the economy also by making direct transfers of resources to a certain group of firms (LeMoglie and Sorrenti, 2020; Mirenda et al., 2019). The resulting estimates of the average sectorial pizzo rate range between 0.5 and 5 percent of the output level of impacted firms. To the best of my knowledge, this paper is the first to provide an explicit estimate of the amount of pizzo imposed by the mafia on firms operating in Northern 
Italy in different industries. These estimates implies that mafia-infiltrated sectors suffer a total loss that ranges between 0.6 and 8 percent of the counterfactual total value added without mafia activity. A crucial finding that emerges from this result is that three-fourths of the aggregate consists of the forgone production due to misallocation. This means that the extortion of pizzo entails a contraction of output that is three times higher than what the mafia actually collects.

Finally, I extend the analysis in order to consider the impact of mafia activity on the Northern Italian economy in a scenario where the mafia targets firms according to their productivity, i.e., where more productive firms have a higher risk of being coerced than less productive ones, and viceversa. The estimates of pizzo obtained in these alternative specifications are in line with those coming from the baseline specification of the model. Under the targeting rule where the most (least) productive firms are more likely to be coerced, the mafia is able to reap larger (smaller) transfers compared to a scenario with random targeting. Going beyond the mere quantification and looking at composition of the loss, I find that, as in the baseline specification of the model, one-fourth of this cost is the aggregate transfer to the mafia while the remaining three-fourths corresponds to the contraction of production due to misallocation. This is a key result of the paper, as the finding that extortion racketeering entails a contraction of output, which is three times higher than what the mafia actually collects, is robust to these alternative specifications of the model (where I relax the assumption of the random targeting rule).

\section{Related literature}

This paper contributes to an emerging body of literature that studies, from a firm level perspective, the economic consequences of weak institutions. Ranasinghe (2017), for example, explores the role of property rights and their link to acts of extortion, while Ranasinghe and Restuccia (2018) quantify the effects of institutional differences in the degree of financial development and the rule of law on aggregate outcomes and economic development. Besley and Mueller (2018) examine the consequences of predation and estimate the welfare loss due to the misallocation of labor across and within firms. Compatibly with this work, I show that extortion perpetrated by the mafia has aggregate effects, and I contribute a new methodology for measuring the economic conse- 
quences of specific idiosyncratic issues, even when they are not directly observable. My study also relates to a number of theoretical and empirical analyses on misallocation. The relationship between firm-level idiosyncratic distortions and aggregate productivity has been theorized by Restuccia and Rogerson (2008) and developed by Hsieh and Klenow (2009), who provide an empirical analysis of resource misallocation to explain cross-country differences in productivity, measured with aggregate total factor productivity (TFP). Bartelsman et al. (2013) take a step further and propose withinindustry covariance between firms' productivity and size as the most instructive index of resource misallocation. Along these lines, I explore how acts of extortion imposed by the mafia on heterogeneous firms can generate resource misallocation. I analyze this relationship directly, in the sense that I study the role of a specific distortion that is idiosyncratic across heterogeneous establishments. ${ }^{3}$ Together with Amodio and Di Maio (2018), my paper is one of the first contributions that applies methods of this well-established literature to a new context: from a cross-country to a "cross-market" analysis.

The analysis also adds, naturally, to the literature on the economic impact of the Italian mafia. Specifically, it develops a link between evidence on aggregate outcomes as studied by Pinotti (2015) and that on micro outcomes as in Mirenda et al. (2019). While several contributions look at the effect of mafia activity on public funds and spending (see for example Daniele and Dipoppa (2019); Galletta (2017); Barone and Narciso (2015); Acconcia et al. (2014)), to date the role of the mafia in the legal economy has received little attention. Mirenda et al. (2019) and LeMoglie and Sorrenti (2020) make a step in this direction, exploring how investments by organized crime in the legal economy can generate a sifnificant rise in the impacted-firm's own revenues and can play a role in the establishment of new enterprises. My analysis is complementary to the works, in that it looks at the other side of the coin, i.e., how criminal organizations infiltrate the legal economy by hampering, rather than financing, firms.

The remainder of the paper is organized as follows. Section 2 overviews the context in which I apply my methodology. Section 3 presents the conceptual framework of the

\footnotetext{
${ }^{3}$ For a comprehensive review of the literature on misallocation and a deeper discussion of the differences between a direct and the indirect approach to the topic, see Restuccia and Rogerson (2013).
} 
analysis. I first describe the OP decomposition of aggregate productivity and explain how idiosyncratic distortions among heterogeneous producers can lower the OP covariance, leading to misallocation. I then present the model of allocative efficiency with idiosyncratic distortions produced by the mafia. In Section 4, I define what is meant by mafia-infiltrated market, introduce the data, and provide empirical evidence of the negative correlation between mafia presence and allocative efficiency. Section 5 presents the empirical method employed to estimate the cost of organized crime. In Section 6, I illustrate my findings and develop a counterfactual analysis that quantifies the cost of mafia activity. Section 7 considers two alternative specifications of the model. Section 8 concludes.

\section{Background: Italian mafia and extortion racketeering}

To provide context to this paper, in this Section I give a brief overview of the criminal activities that the Italian mafia perpetrates, of how important pizzo is in relation to the other ways in which the mafia affects the economy, and of its presence in territories different than its historical settlements, i.e. the northern Italian regions.

The appearance of the first mafia-type organizations can be traced back to the second half of the Nineteenth century in southern regions such as Sicily, Calabria, Campania, and Apulia as suppliers of private protection (Buonanno et al., 2015; Skaperdas, 2001). Nowadays, the mafia engages in a wide range of activities, that goes from extortion racketeering to the manufacturing and marketing of illegal goods and services (such as drugs, gambling, and prostitution), or the direct investment in the legal economy (LeMoglie and Sorrenti, 2020; Mirenda et al., 2019). These businesses can produce huge revenues. ${ }^{4}$ While other types of activities performed by the mafia might be more profitable than extortion racketeering, the stable practice of extortion in a given territory is the hallmark of each mafia-type organization (La Spina et al., 2014). Specifically, a ter-

\footnotetext{
${ }^{4}$ For example, The Italian Ministry of Internal Affairs (Transcrime, 2013) has estimated that the annual turnover of the Italian mafia from drug trafficking is 7.7 billion euros. This is the most profitable activity, followed by extortion ( 4.7 billion euros), sexual exploitation ( 4.6 billion euros) and counterfeiting (4.5 billion euros).
} 
ritory is affected by actual mafia-rootedness (in Italian, radicamento mafioso) if and only if the mafia perpetrates regularly extortion racketeering. Otherwise, we talk about by mafia-incursions, i.e. when the mafia engages only in activities like money laundering and other business without settling permanently (Confesercenti, 2012).

La Spina et al. (2014) provide an accurate illustration of how the imposition of pizzo works in the real word, using actual data on extortion racketeering. ${ }^{5}$ The process of extortion can be divided in three different phases: the first approach where the mafia reaches and intimidates its victim; the negotiation phase when there might be some bargaining between the victim and the perpetrator (however, it emerges from the data that this phase occurs rarely), and the demand/consumption phase when the mafia gets what was asked to the victim, i.e. when pizzo is actually collected. This last phase can take several forms. First of all, the extortion request can be periodic, when the mafia asks the victim pizzo regularly (e.g. every months, or during the main public holidays such as Christmas and Easter), or it can be episodic, i.e. it is a one-off event. Moreover, the actual payment of pizzo can be made in various ways: the mafia can extort money or goods (this form is defined as parasitic request) or it can impose to its victim some specific performances such as purchase of specific goods and services, recruitment of employees, restrictions and limitation of the normal economic activity (in this case the extortion act is defined as active). In the theoretical framework presented in Section 3, I model the imposition of pizzo as an episodic and parasitic request.

It is widely known that the mafia has gone beyond the borders of its settlements to reach the whole Italian territory (Varese, 2011). The spread of mafia in northern Italy has evolved over time. At a first stage, the mafia started controlling and coordinating illegal markets (drugs, prostitution, gambling), especially where there was no local criminal groups capable of managing them. An aspect that can explain how spread of the mafia to the Northern Italian provinces started is the interaction between the Italian Confino system and the influx of southern workers into northern regions (Buonanno

\footnotetext{
${ }^{5}$ Their analysis is based on extortion acts occurred in Sicily. The authors produced a database making use of interviews with victims of extortions and judicial sources.
} 
and Pazzona, 2014). ${ }^{6}$ After this first phase, the mafia started moving people and financial resources in order to establish an organization capable of attacking the legal economy. Confesercenti (2012) indicates as specific areas that facilitated this penetration the gambling sector, the credit market, the construction sector, sectors that relies on unskilled labor (Dipoppa, 2021; Scognamiglio, 2018), and, most importantly, the public procurement system (Piemontese, 2013; Calderoni and Caneppele, 2009). In fact, on the one hand the mafia is able to directly affect the awarding of public contracts (Barone and Narciso, 2015). On the other hand, when it comes to major infrastructure projects awarded by large contractors (e.g. the European Union), mafia groups localized in the territories that receive public funding can either impose subcontracts, or guarantee themselves the control over the infiltrated territories by perpetrating regularly pizzo racketeering. In Section 4, I make use of this argument and evidence presented in Confesercenti (2012) and Piemontese (2013) to determine which northern territories are infiltrated by the mafia.

\section{Conceptual Framework}

The mafia impacts economic activity by altering the optimal decisions of a certain number of firms, i.e., those that are forced to pay pizzo. Since I model pizzo as a proportional tax on the value of output, impacted firms reduce their size-compared to the scenario without the mafia—and may end up being smaller than firms with lower innate productivity. This idiosyncratic distortion thus has aggregate effects as it biases the allocation of resources among all the firms in the infiltrated markets. ${ }^{7}$

Before describing theoretically the mechanism through which extortion racketeering can alter allocative efficiency, I introduce the index used in this analysis to detect possible misallocation: the within-industry covariance between productivity and size derived by the decomposition of aggregate productivity established by Olley and Pakes

\footnotetext{
${ }^{6}$ Confino was a particular Italian policy measure implemented in the late 70s that imposed the compulsory displacement of people strongly suspected of belonging to mafia-like organizations.

${ }^{7}$ The fact that only a group of firms is subject to racketeering makes this distortion idiosyncratic.
} 
(1996).

\section{The OP decomposition}

The OP decomposition is derived from a measure of aggregate productivity introduced by Olley and Pakes (1996). In this seminal contribution, aggregate productivity is the weighted sum of firms' productivity, where the weight is firms' size. This index can be decomposed into two components: the unweighted average of firms' productivity and a covariance component, which measures the extent to which most productive firms are larger than the less productive ones.

Consider a market, defined as an industry in a given location observed at a given point in time, populated by $N$ firms. The cross-section aggregate productivity is defined as follows:

$$
\Omega \equiv \sum_{i \in N} \theta_{i} \omega_{i}=\bar{\omega}+\sum_{i \in N}\left(\left(\theta_{i}-\bar{\theta}\right)\left(\omega_{i}-\bar{\omega}\right)\right)
$$

where $\Omega$ is the aggregate productivity of the market, $\omega_{i}$ and $\theta_{i}$ are firm-level productivity and size, respectively, and a "bar" over a variable represents the unweighted average of the firm-level measure. Thus, the first term of the right hand side $\bar{\omega}$ is the unweighted average productivity of the $N$ firms operating in this market, and the second term is the so-called OP covariance between productivity and size of the $N$ firms.

Proposition 1 helps to see the role of $\mathrm{OP}$ covariance in increasing aggregate productivity and why it can be used as an informative measure of resource misallocation. The proof is provided in Appendix A.1.

Proposition 1 Consider the vector $\omega$ containing $N$ firm-level productivity ranked as follows $\omega_{1}>\omega_{2}>\omega_{3}>\ldots>\omega_{N}$, and the vector $\theta$ containing $N$ of firm-level size ranked as follows $\theta_{I}>\theta_{I I}>\theta_{I I I}>\ldots>\theta_{N}$. If aggregate productivity is defined as the sum of firm-level productivity weighted by firm-level size, the way to maximize it is to match $\omega_{1}$ to $\theta_{I}, \omega_{2}$ to $\theta_{I I}$, and so forth. Therefore, a market where aggregate productivity is maximized is a market in which there is no misallocation. 
This proposition simply says that aggregate productivity is maximized when the rankings of firm productivity and firm size are perfectly aligned, i.e., when the most productive firm is also the largest one, the second most productive is the second largest one, and so forth. A market where these rankings are not aligned is a market affected by resource misallocation. In this case, aggregate productivity would increase by reallocating production inputs to more productive firms, implying a higher OP covariance and, in turn, a higher aggregate productivity. In the next sub-section I link this concept to mafia infiltration, explaining how extortion acts impacting certain firms can have aggregate effects, weakening the strength of the link between firms' productivity and firms' size.

\section{The model}

My modeling of how distortions introduced by the mafia lead to resource misallocation shares common features with Hsieh and Klenow (2009) and Bartelsman et al. (2013). Firms are heterogeneous in their level of productivity and face idiosyncratic distortions. The curvature in the profit function, necessary for an equilibrium of firms with heterogeneous productivity, comes from decreasing returns to scale and a downward sloping demand curve implied by a monopolistic competition environment. Further, as in Bartelsman et al. (2013), the model includes overhead labor as a part of the technology, in order to guarantee that the distribution of labor productivity is not degenerate even in an economy with no distortions.

Consider an economy defined by $p \times t$ markets, where each market consists of a specific geographical area $p$ at a given point in time $t$. Assume that the final aggregate output $Y_{p t}$ is produced by a representative firm that operates in a perfectly competitive market: the final good is sold at price $P$, which is taken as given. To produce $Y_{p t}$, this single representative firm combines $s$ intermediate outputs $Y_{s}$ produced from all $S$ sectors of the economy in a Cobb-Douglas technology:

$$
Y_{p t}=\Pi_{s=1}^{S} Y_{s}^{\theta_{s}}
$$

with $\sum_{s=1}^{S} \theta_{s}=1$. Given that the final good price $P$ is taken as given, cost minimization implies that $P_{s} Y_{s}=\theta_{s} P Y$ for every sector $s$, where $P_{s}$ is the sector specific price of the 
intermediate output $Y_{s}$.

In each sector $s$ the production of the intermediate output $Y_{s}$ is carried out by a single representative firm that combines $N_{S}$ differentiated inputs in a CES production function. Every input $Y_{i}$ is supplied by firm $i$ at price $P_{i}$ in monopolistic competition. ${ }^{8}$ Industry $s$ production is given by:

$$
\begin{aligned}
Y_{S} & =\left(\sum_{i \in N_{s}} Y_{i}^{\frac{\sigma-1}{\sigma}}\right)^{\frac{\sigma}{\sigma-1}} \\
& =\left(\sum_{i \in N_{s}} Y_{i}^{\gamma}\right)^{\frac{1}{\gamma}}
\end{aligned}
$$

where $\sigma>1$ is the elasticity of substitution between any two varieties. For computational simplicity $\sigma$ is rewritten as $\frac{1}{1-\gamma}$, with $\gamma<1$.

In each industry s (located in area $p$ at time $t$ ) the $N_{s}$ firms produce differentiated products in a monopolistic competition regime. Firm $i$ 's production technology has labor as unique input, includes overhead labor, and exhibits decreasing return to scale:

$$
Y_{i}=\Gamma_{p t} A_{i}\left(L_{i}-f_{s}\right)^{\alpha}
$$

with $\alpha$ smaller than one due to decreasing returns to scale.

I make the following assumptions: (i) firm $i$ 's productivity has a firm-specific component $A_{i}$, i.e., total factor productivity (TFP), which can be seen as firm-level innate and permanent ability, and a time varying area-specific exogenous component $\Gamma_{p t}$ that captures all the area-time specific factors affecting the production of every firm in every industry $s$ in the same way, e.g., province-specific change of institutions, or funding for major infrastructure project; (ii) the firm-specific productivity component $A_{i}$ is drawn from a log-normal distribution with average $\mu_{s p}$ and standard deviation $\sigma_{s p}$, meaning that the moments of TFP are sector-province-specific but time invariant, capturing the idea that different provinces specialize in different sectors; and (iii) overhead labor $f_{s}$ is

\footnotetext{
${ }^{8}$ Note that both $Y_{S}$ and $Y_{i}$ are time dependent. I do not include the time subscript $t$ for notation simplicity.
} 
exogenously determined and sector-specific. ${ }^{9}$

In line with what presented in Section 2, I model extortion acts as episodic and parasitic requests. Specifically, the mafia enters this scenario by imposing pizzo on a certain group of firms. I let firms of different sizes to be subject to different pizzo rates (Balletta and Lavezzi, 2019). Therefore, since some firms are subject to racket and others are not, mafia infiltration introduces an idiosyncratic distortion.

In the baseline specification of my model, I assume that the mafia targeting of firms is random, i.e. the fact that firm $i$ is coerced by the mafia is unrelated to its productivity. Indeed, given that the effective establishment of the mafia in northern territories is a relatively recent phenomenon, and it involves a relatively low share of firms if compared to the southern regions (see Section 2), it is plausible to assume that the mafia is not able to observe firm-level productivity. Yet, since there is still scarce evidence on the functioning of the mafia in northern regions, in Section 7 I relax this assumption and consider two alternative targeting rules and assume that mafia impact is positively/negatively correlated with firm productivity. ${ }^{10}$

I model pizzo as a proportional tax on output. This output distortion results from the interaction of two terms. I call the first component "mafia exposure" parameter $\tau_{i}$. It is Bernoulli distributed with mean $\lambda$. This is a dummy variable that equals one if firm $i$ is subject to racket and zero otherwise. The second element, called "mafia intensity" component, which measures the share of output that the mafia extorts, is given by $\delta_{i}$. Specifically, I follow the evidence presented in Balletta and Lavezzi (2019) and assume that firm-specific pizzo rate is decreasing in firm's size. ${ }^{11}$

Note that this formulation also allows for a different type of mafia infiltration, i.e., when

\footnotetext{
${ }^{9}$ The log-normal distribution assumption is consistent with evidence provided by Angelini and Generale (2008) and Donati and Sarno (2015).

${ }^{10}$ Expectedly, in the empirical analysis of this paper, by changing this assumption I obtain different measures of the total loss implied by mafia extortion racketeering. This means that the estimates obtained in this paper should be considered as ranges. Yet, what is really important is that the composition of the loss, i.e. the share due to misallocation and the share due to transfer of resources to mafia groups, remains unchanged in every specification of the model.

${ }^{11}$ In their analysis, Balletta and Lavezzi (2019) assume that the mafia extorts all firms in the market and the object of choice is how much to charge each firm. They exploit a unique dataset on extortion in Sicily, which allows them to observe the exact amount of pizzo that each coerced firm has transferred to the mafia and estimate the elasticity of pizzo rate with respect to firm-specific size.
} 
the mafia transfers directly resources to firms, instead of extorting pizzo. In the empirical analysis, I control for this possibility by letting a certain group of firms to be infiltrated by the mafia (with transfer of resources) following Mirenda et al. (2019).

If the mafia infiltrates the market, firm's $i$ profit is:

$$
\Pi_{i}=\left(1-\tau_{i} \delta_{i}\right) Y_{i} P_{i}-w_{s t} L_{i}
$$

where $w_{s t}$ is the cost of labor. I assume that $w_{s t}$ is exogenous and that it changes over sector and time but not across provinces. ${ }^{12}$ Note that in this scenario, the minimization problem of each firm is static, i.e., there is no link between current profit-maximizing decisions and choices made in other time periods. Pizzo can be seen as a one-off tax, i.e., as explained in Section 2, a payment that is not demanded regularly but on sporadic occasions.

Profit maximization under monopolistic competition with product differentiation yields the standard condition that firm's output price $P_{i}$, which is endogenous to $Y_{i}$, is a fixed mark-up over the cost of labor:

$$
P_{i}=\left[\frac{1}{\gamma}\right]^{\frac{\alpha(1-\gamma)}{1-\alpha \gamma}}\left[\frac{w_{s t}}{\alpha} \frac{1}{\left(1-\tau_{i} \delta_{i}\right)}\right]^{\frac{\alpha(1-\gamma)}{1-\alpha \gamma}}\left[\frac{1}{\Gamma_{p t} A_{i}}\right]^{\frac{(1-\gamma)}{1-\alpha \gamma}}
$$

Optimal labor demand and output are given by:

$$
\begin{gathered}
\left(L_{i}^{*}-f_{s}\right)=\left[\frac{\alpha \gamma}{w_{s t}}\left(1-\tau_{i} \delta_{i}\right)\right]^{\frac{1}{1-\alpha \gamma}}\left[\Gamma_{p t} A_{i}\right]^{\frac{\gamma}{1-\alpha \gamma}} \\
Y_{i}=\left[\frac{\alpha \gamma}{w_{s t}}\left(1-\tau_{i} \delta_{i}\right)\right]^{\frac{\alpha}{1-\alpha \gamma}}\left[\Gamma_{p t} A_{i}\right]^{\frac{1}{1-\alpha \gamma}}
\end{gathered}
$$

Equations 6, 8, and 7 are combined to derive the expression of labor productivity:

\footnotetext{
${ }^{12}$ This assumption is compatible with the fact that, in Italy, wages are mainly established through collective bargaining. Thus, in every industry they are homogeneous, at least across the northern regions.
} 


$$
L P R_{i}=\frac{P_{i} Y_{i}}{L_{i}^{*}}=\left[\frac{w_{s t}}{\alpha \gamma} \frac{1}{\left(1-\tau_{i} \delta_{i}\right)}\right]-\left[\frac{w_{s t}}{\alpha \gamma} \frac{f_{s}}{\left(1-\tau_{i} \delta_{i}\right) L_{i}^{*}}\right]
$$

This simple expression for labor productivity, which I use as measure of firm-level productivity, yields several implications. First, in the absence of mafia infiltration, i.e., in an economy with no distortions, labor productivity varies across firms. This happens because firm-technology includes overhead labor. Second, in absence of distortions, labor productivity is increasing in size, measured by employment. This means that the distributions of firms' productivity and firms' size are perfectly correlated, i.e., the most productive firm is the largest one that has the highest level of employment. Therefore, according to Proposition 1, the OP covariance measured in terms of labor productivity and employment is maximized. Third, the idiosyncratic distortions brought on by mafia infiltration weakens this relationship. In particular, according to Equation 9, it is not necessarily true that the distributions of firms' productivity and size are perfectly aligned. Following Proposition 1, if this is the case, the market is affected by resource misallocation and the OP covariance characterizing this environment is lower than that computed in the corresponding scenario without mafia. ${ }^{13}$ This means that extortion racketeering of a certain number of firms perpetrated by the mafia has aggregate effects.

In the empirical analysis that follows, I provide suggestive evidence of the negative correlation between mafia presence and allocative efficiency discussed here. I then implement a structural estimation where I back out the amount of pizzo $\delta_{i}$ extorted in every infiltrated market from the OP covariance (in terms of LPR and employment to measure shares) characterizing these markets.

\footnotetext{
${ }^{13}$ The same reasoning can be applied in looking at Equation 8 and considering the OP covariance computed using TFP and output to measure productivity and shares, respectively. In this paper I compute OP covariance using labor productivity and employment as arguments, as their computation requires information widely available in firm-level datasets, that is less subject to measurement error than variables such as capital or total factor productivity.
} 


\section{Definitions, Data, and Preliminary Evidence}

In this section, I define what is meant by a mafia-infiltrated market as well as present the data. Using this information, I then explore empirically the relationship between mafia presence and allocative efficiency in a regression that exploits the three-dimensional variation of mafia infiltration.

\section{Mafia-infiltrated markets}

I focus on Northern Italy, a territory where mafia activity has only became pervasive in the past few decades (Varese, 2011), and is not yet entirely infiltrated by organized crime (Confesercenti, 2012). As northern Italy is characterized by homogeneous social and economic conditions, this area provides an ideal setting for my analysis. My definition of mafia-infiltrated markets involves three dimensions: geographic, temporal, and sectorial. Specifically, mafia-infiltrated markets are certain sectors of the economy in mafia-infiltrated provinces and observed after mafia arrival.

Given that a mafia-infiltrated market is an industry located in a mafia-infiltrated province after the arrival of the mafia, it is necessary to define how and when a province is infiltrated by mafia. As discussed in Section 2, mafia infiltrations are strongly linked to the public procurement sphere. This matter has been receiving considerable attention both from the academic community (Calderoni and Caneppele, 2009) and the media (e.g. inquiries related to the A3 Salerno-Reggio Calabria motorway) and is considered as one of the main factors that favors mafia settlement in new territories (Confesercenti, 2012). In this perspective, I follow Piemontese (2013), who explores the role of public investment in infrastructure on mafia expansion in Northern Italy. The paper shows that there was a significant increase in extortion cases in the provinces that received funding for the modernization of the A4 motorway and for the construction of the high-speed railway between Milan and Bologna, after their approval between 2000 and 2002. Therefore, I define as infiltrated provinces those that received public funding for the renewal of the Turin-Trieste highway and/or the Milan-Bologna railway. These provinces are visible in Figure 1, which maps the northern territories and the infrastructure studied by Piemontese (2013). With the exception of a single province, i.e. Venice, each province that I define as mafia-infiltrated belongs to the regions that Confesercenti 
(2012) indicates as impacted by effective mafia rooting, i.e. Piedmont, Lombardy, and Emilia-Romagna. ${ }^{14}$ For each infiltrated province, the mafia period starts the year of the approval of the public funding (2000 for some provinces and 2002 for the rest).

Figure 1: Provincial mafia presence

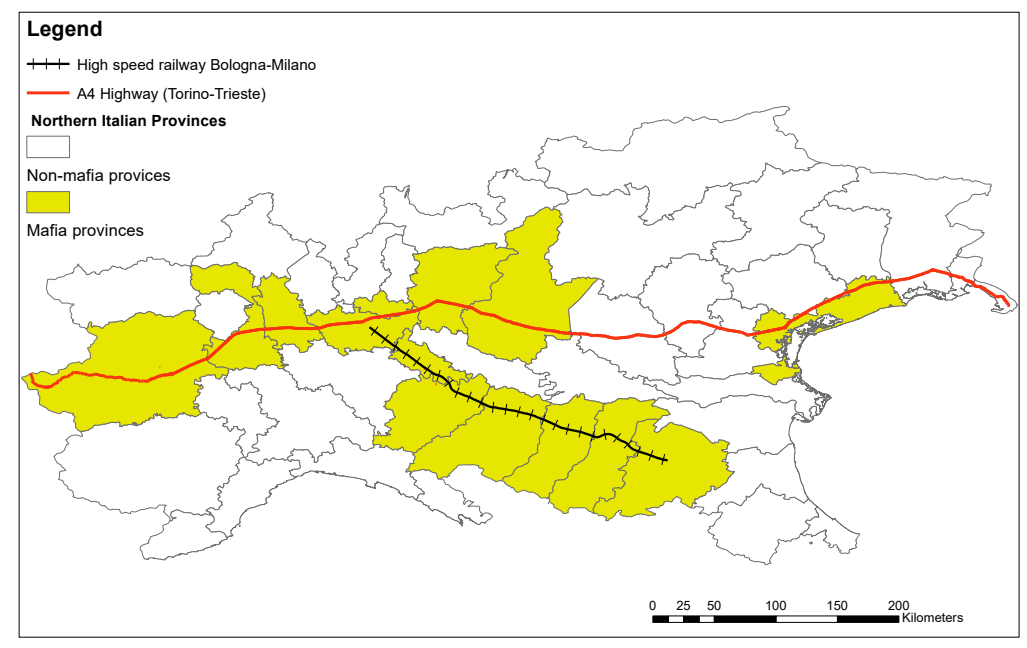

This map shows the Northern Italian provinces (NUTS 3). The red line depicts the A4 highway that connects the Province of Turin to the Province of Trieste. The black dashed line represents the Milan-Bologna high-speed railway. Provinces highlighted in yellow are those defined as mafia-infiltrated, whereas the others are non-mafia provinces. The territories crossed by the A4 highway that are not highlighted in yellow are those provinces that did not received any funding for the renewal of the road, i.e., only some stretches were modernized.

Given the little available work on mafia diffusion in Northern Italy, there is no scholarly consensus on when exactly the mafia migrated towards the northern regions and when it effectively settled. As introduced in Section 2, several studies argue that the mafia began moving to the North as early as the late 70s, due both to legal practices forcing suspected mafiosi (people linked to the mafia) to relocate to towns historically unaffected by the mafia and to migration flows from Southern Italy (Scognamiglio, 2018; Buonanno and Pazzona, 2014; Varese, 2011). ${ }^{15}$ The assumption of these studies of an earlier entry does not necessarily contradict that of a later arrival used here. In fact, even if mafiosi

\footnotetext{
${ }^{14}$ The remaining northern regions, i.e. Aosta Valley, Liguria, Veneto, Trentino-Alto Adige, and FriuliVenezia Giulia, show a less aggressive and steady mafia presence.

${ }^{15}$ Although Buonanno and Pazzona (2014) and Scognamiglio (2018) focus on northern and central regions, their results do not specifically refer to the regions under the analysis here.
} 
reached the North before the 2000s, it is plausible to assume a time lag between mere arrival and the effective infiltration of the legal economy, which boomed in the early 2000s.

Finally, in order to define the specific sectors into which the mafia has spread, I use information on firms confiscated by the judicial system because they were found to be directly managed or linked to the mafia, between 1993 and 2015. These data, provided by the National Agency for the Administration and Management of Assets Seized and Confiscated from Organized Crime (ANBSC), reports information on the location and the sector of the confiscated firm, as well as the year of the final verdict of confiscation. Figure 2 ranks seven sectors of the economy according to the absolute and relative number of firms (amount per 10,000 firms) located in the northern provinces that have been seized from the mafia. Industries with a fairly large number of confiscations, displayed in the figure with bright colors, are defined as mafia infiltrated. In particular, these sectors include: wholesale and retail trade, accommodation and food services, construction, real estate activities, and community, social, and personal services. This is largely compatible with the sectoral distribution of the mafia presented by Mirenda et al. (2019). In order to confirm that my definition of mafia-infiltrated market does indeed capture

Figure 2: Sectorial mafia presence

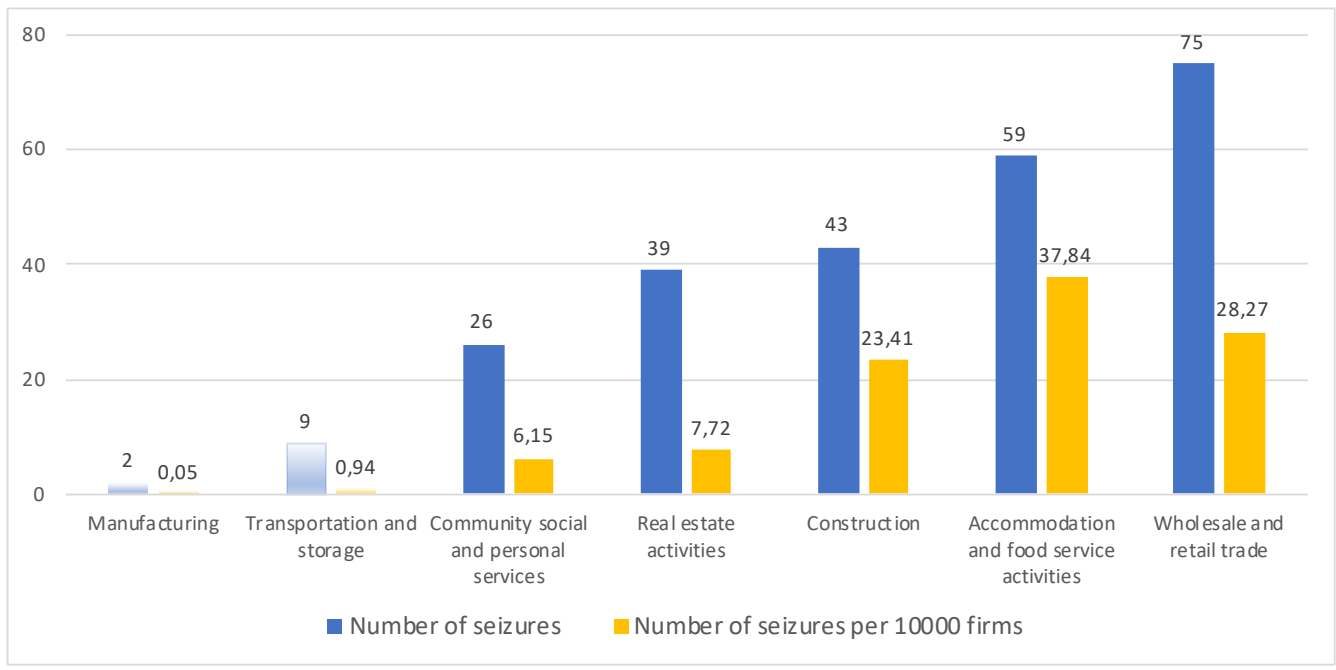

Source: Computations based on ANBSC information on firms seized from the mafia. The blue bars depict the total number of confiscations of firms located in Northern Italy, for each of the seven sectors studied in this paper. The yellow bars reflect the relative size of each sector, reporting the number of confiscation per 10,000 firms. The bars plotted with brighter colors represent sectors that are defined as mafia infiltrated. The remaining bars, depicted with lighter colors, represent the non-mafia sectors, or those that have a negligible number of confiscations from organized crime. 
the spatial and temporal dimensions of mafia spread in Northern Italy, I perform a validation exercise in Appendix A.2. In particular, I perform a difference-in-differences analysis where I show that, on average, the confiscation of firms from the mafia (measured using the data from ANBSC, plotted in Figure 2) increased in provinces defined as infiltrated, after mafia arrival, compared to the remaining northern territories. ${ }^{16}$

\section{Data}

For the purpose of this analysis I combine data from two main sources. The first is the Small and Medium Enterprise Survey (SME), a yearly representative survey on small and medium enterprises registered in the Italian Statistical Business Register (ASIA), administered by the Italian National Institute of Statistics (ISTAT). The time span covered is 1998-2012. ${ }^{17}$ As my analysis focuses on Northern Italy, I consider only information on firms operating in this part of the country. The resulting sample comprises between 20,000 and 29,000 firms per year and includes information on each firm's location (at the province level), sector, number of employees, revenue, and expenditure in intermediate inputs. ${ }^{18}$ Unfortunately, the data provider's confidentiality requirements necessitated aggregating the information at the sector-province-year level, such that I loose data at the firm level. I consequently perform my analysis on the resulting panel, where the individual dimension is given by the sector-province-year triplet. The panel provides information on the 46 Northern Italian provinces, for 7 industries, from 1998 to 2012. To carry out the empirical analysis described in Section 5, I construct the following variables: mean and variance of labor, mean and variance of value added, mean and variance of value added per worker (all of which are computed both in levels and logs), and number of firms. Finally, I construct the OP covariance in terms of $(\log )$ value added per worker and share of employment over total employment.

\footnotetext{
${ }^{16}$ This result is robust to several alternative specifications. Specifically, I estimate regressions with different groups of fixed effects, i.e. region fixed effects and province fixed effects.

${ }^{17}$ The data can only be accessed and processed at the research center Laboratory for Elementary Data Analysis (ADELE), managed by ISTAT.

${ }^{18}$ Sectors are defined according to ISIC activity Rev. 4. Revenues and expenditure in intermediate inputs are weighted with an industry-level deflator, which are gathered from the EU KLEMS Growth and Productivity Accounts: 2012 Release.
} 
Second, I measure mafia intensity using information on reports of extortion provided by the Annual Criminal Statistics Report published by the Italian Statistical Institute (ISTAT). This information was gathered at the province-year level, for the years 1990-2012. The left panel of Figure 3 shows the average extortion cases over time for two groups of observations: mafia and non-mafia provinces, i.e. provinces crossed by the renewed A4 motorway and by the Milan-Bologna high-speed railway, and the remaining ones. Overall, the number of average yearly extortion cases in mafia provinces (black solid line) is greater than in the non-mafia provinces (black dashed line). Further, there is a clear change in the trend of average extortion cases in mafia provinces around the year 2004 , i.e. a few years after the approval of the public funding for infrastructure (occurred between 2000 and 2002) used to distinguish mafia-infiltrated provinces from the others.

I use this information to compute the yearly share of firms subject to extortion racketeering for every province defined as mafia infiltrated, i.e. $\lambda_{p t}$. In particular, the numerator of $\lambda_{p t}$ is the increase in reports of extortion registered in the infiltrated provinces after mafia arrival, relative to non-mafia provinces. ${ }^{19}$ The way $\lambda_{p t}$ is constructed implies that this paper quantifies the economic consequences of the increase of mafia activity that occurred in mafia-infiltrated provinces after the settlement of organized crime in the northern regions, as shown in Piemontese (2013).

Mafia activity is thought of here as an extra component of allocative efficiency, which plays a role only in mafia sectors, located in the infiltrated provinces, after organized crime arrival. I rely on this point in what follows. First, I provide suggestive evidence of a negative correlation between mafia presence and allocative efficiency, measured with the OP covariance. Then, I implement a structural estimation where I compute the parameters of the model that are unrelated to mafia and next, back out the amount of pizzo imposed on impacted firms from the OP covariance that characterizes the infiltrated markets, given the share of impacted firms.

\footnotetext{
${ }^{19}$ Further details on the construction of $\lambda_{p t}$ are provided in Appendix A.3.
} 


\section{Suggestive evidence}

In a preliminary exploration of the data, I analyze the relationship between mafia presence and resource misallocation by performing an empirical strategy, which employs the three-dimensional variation of the data, i.e. sector-province-year. In particular, I compare the average allocative efficiency of the infiltrated provinces to that of the remaining northern territories, in mafia sectors and in the other sectors of the economy, over time. To this end, I estimate the following regression:

$$
\text { OPcovariance }_{s p t}=\alpha+\sum_{t} \beta_{t}\left(\text { mafia }_{p s} \times \text { year }_{t}\right)+\theta_{p}+\theta_{t}+u_{s p t}
$$

where the left hand side is the OP covariance in terms of $(\log )$ labor productivity and share of employment over total industry employment. Variable mafia ${ }_{p s}$ denotes a dummy that varies at sector-province level and equals one if sector $s$ is mafia infiltrated and is located in an infiltrated province $p$. This dummy is interacted with each available time dummy year ${ }_{t}$, this means that the resulting interaction terms have a three-dimensional variation (sectorial, spatial, and temporal). Finally, $\theta_{p}$ and $\theta_{t}$ are province, and time fixed effects respectively. The right panel of Figure 3 plots the estimates of the $\beta_{t} \mathrm{~s}$ included in Equation 10, i.e., $\beta_{1998}, \beta_{1999}, \ldots, \beta_{2012}$, together with their $95 \%$ confidence bands. ${ }^{20}$ These coefficients follow a clear decreasing trend. ${ }^{21}$ These results point to the existence of a negative correlation between mafia presence and allocative efficiency. Interestingly, the decrease in the trend begins around the year 2004, i.e., the same time period when the sharp increase in extortion cases occurred in the infiltrated provinces, as shown in the left panel of Figure 3.

Even if limited, this result can be seen as motivating evidence of the idea that there exists a correlation between misallocation and mafia presence. The next step of the analysis is to bring the theoretical explanation of the mechanism through which mafia

\footnotetext{
${ }^{20}$ Standard errors are clustered at the province level.

${ }^{21}$ The magnitude of the estimates is robust to the inclusion of province-year fixed effects. However, most of the betas lose statistical significance, likely due to the sizable reduction in variation implied by the high number of fixed effects.
} 
infiltration is linked resource misallocation to the data, and compute the welfare loss of mafia infiltration.

Figure 3: Extortion and misallocation
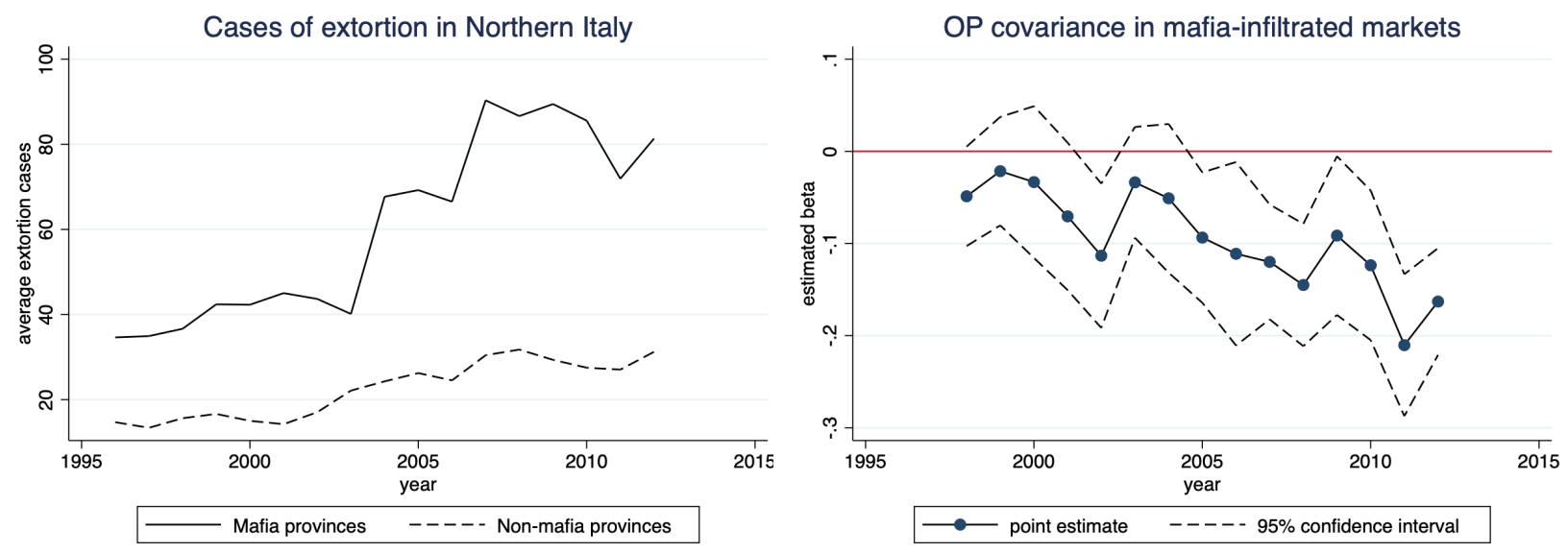

Source: Computations based on ISTAT Yearly Book of Criminal Statistics (ed. 2014). Left panel: the black solid line reports the average number of extortion cases that occurred in mafia-infiltrated provinces between the years 1990 and 2012. The black dashed line reports the average number of extortion acts in non-mafia provinces in the years 1990-2012. A longer time series than that of the main analysis is used to verify the absence of pre-trends. Right panel: this figure plots the parameters estimated from Equation 10 (blue dots) together with their $95 \%$ confidence intervals (dashed black lines), derived from standard errors clustered at the province level. The dependent variable of the regression is the OP covariance (measured with $(\log )$ labor productivity and share of labor over total labor). Each blue dot is the coefficient of the interaction between each single time dummy (1998 to 2012) and a dummy that varies at the sector-province level, equal to one if both the sector and province are defined as mafia-infiltrated, according to the definition provided above.

\section{Empirical strategy}

This section describes how I bring the model presented in Section 3 to the data, through a structural estimation consisting of two main stages. First, I use information on noninfiltrated markets to estimate all the parameters of the model that are unrelated to the mafia. I then feed a structural model with these parameters and actual data on mafia presence (i.e., the share of firms subject to extortion racketing) in order to quantify, for each infiltrated sector-province-year, the amount of pizzo that impacted firms are forced to transfer to the mafia. Specifically, the two stages of the analysis comprise:

- OLS regressions to estimate the following parameters (presented in Section 3): (i) mean and standard deviation of firms' TFP, $\mu_{s p}$, and $\sigma_{s p}$; (ii) the component of firms' productivity that is province-time specific, $\Gamma_{p t}$; (iii) exogenous macroeconomic variables such as wages and overhead labor, i.e. $w_{s t}$ and $f_{s}$. 
- MSM, which uses the parameters estimated in the previous stage to quantify the amount of pizzo imposed in every infiltrated sector-province-year, i.e. $\delta_{s p t}$.

\section{First stage}

In this stage, I focus on non-mafia markets, i.e., markets that are not defined as mafia infiltrated. Since, as explained in Section 4, this definition has a sectorial, a territorial, and a temporal variation, I can define a group of $N_{N M}$ markets composed of: (i) sectors that are not infiltrated, in every Northern Italian province, observed during the years 1998-2012; (ii) mafia-infiltrated sectors, located in non-mafia provinces, observed during the years 1998-2012; (iii) mafia-infiltrated sectors, in mafia-infiltrated provinces, before mafia arrival, i.e., before 2000 for some mafia infiltrated provinces and before 2002 for the remaining provinces.

I use data on these $N_{\mathrm{NM}}$ sector-province-year in order to estimate two sets of parameters introduced in the theoretical model presented in Section 3. The first group contains the parameters related to firms' productivity, i.e., $\mu_{s p}, \sigma_{s p}$, and $\Gamma_{p t}$. The first two parameters are the mean and the variance of the log-normal distribution of the firmlevel productivity component. These moments are assumed to be time-invariant, and sector-province specific. The idea is that these parameters identify the distribution of permanent unobserved heterogeneity in firm-level productivity, and the fact that they are sector-province specific means that different provinces can specialize in various sectors. The third parameter is the productivity component common to every firm located in a given province $p$ at time $t$. This element captures any time specific productivity shock that impacts in the same way all the firms located in a given province. The second set of parameters includes the exogenous macroeconomic variables, i.e., wages $w_{s t}$, which is sector-time specific, and overhead labor $f_{s}$, which is sector specific and time invariant.

The three-dimensional structure of the data and the assumptions made on the variation of these parameters allow me to use non-mafia markets as the best counterfactual of infiltrated markets without mafia activity. In fact, I exploit the sector-province variation of mafia sectors and provinces before mafia arrival to estimate $\mu_{s p}$ and $\sigma_{s p}$. Likewise, I estimate $\Gamma_{p t}$ by exploiting the province-time data variation on non-mafia sectors. Finally, 
wage $w_{s t}$ and overhead labor $f_{s}$ are computed exploiting the sector-time and sector variation of data on non-mafia provinces and mafia-infiltrated provinces before mafia arrival. I estimate these parameters with OLS regressions, whose equations are derived using the results of the model presented in Section 3. First, I compute from firm-level value added as the product of firm-level equilibrium price and output (Equations 6 and 8 respectively) in a scenario without the mafia:

$$
V A_{i}=\left[\frac{\alpha \gamma}{w_{s t}}\right]^{\frac{\alpha}{1-\alpha \gamma}}\left[A_{i} \Gamma_{p t}\right]^{\frac{\gamma}{1-\alpha \gamma}}
$$

Consequently, firm i's log-value added is:

$$
\log \left(V A_{i}\right)=\frac{\alpha}{(1-\alpha \gamma)}\left[\log (\alpha \gamma)-\log \left(w_{s t}\right)\right]+\frac{\gamma}{(1-\alpha \gamma)}\left[\log \left(A_{i}\right)+\log \left(\Gamma_{p t}\right)\right]
$$

Further, an expression for value added as a function of optimal labour can be derived using Equations 9 and 7:

$$
V A_{i}=\frac{1}{\alpha \gamma} w_{s t}\left(L_{i}^{*}-f_{s}\right)
$$

Second, since I use aggregate data at the sector-province-year level, I have to derive aggregate expressions from Equations 11, 12, and 13. In particular, I compute average and variance of log-value added, and average value added in levels, as a function of labor. I express these moments as follows:

$$
\overline{\log (V A)}_{s p t}=\frac{\alpha}{(1-\alpha \gamma)}\left[\log (\alpha \gamma)-\log \left(w_{s t}\right)\right]+\frac{\gamma}{(1-\alpha \gamma)} \log \left(\Gamma_{p t}\right)+\frac{\gamma}{(1-\alpha \gamma)} \tilde{\mu}_{s p}
$$

where $\tilde{\mu}_{s p}$ is the mean of $\log \left(A_{i}\right)$ that is province-sector specific.

$$
\operatorname{VAR}(\log (V A))_{s p t}=\left[\frac{\gamma}{(1-\alpha \gamma)}\right]^{2} \tilde{\sigma}_{s p}^{2}
$$

where $\tilde{\sigma}_{s p}^{2}$ is the variance of $\log \left(A_{i}\right)$ that is province-sector specific.

$$
\overline{V A}_{s p t}=\frac{1}{\alpha \gamma} w_{s t}\left(\bar{L}_{s p t}-f_{s}\right)
$$

Finally, I run the following OLS regressions:

$$
y_{1, s p t}=\theta_{s t}+\theta_{p t}+\theta_{s p}+u_{1, s p t}
$$


where $y_{1, \text { spt }}$ is the average of $(\log )$ value added in each sector-province-year, i.e., the left hand side of Equation 14, and $\theta_{s t}, \theta_{p t}$, and $\theta_{s p}$ are sector-time, province-time, sectorprovince fixed effects respectively.

$$
y_{2, s p t}=\eta_{s t}+u_{2, s p t}
$$

where $y_{2, s p t}$ is the variance of $(\log )$ value added in each sector-province-year, i.e., the left hand side of Equation 15, and $\eta_{s t}$ are sector-time fixed effects.

$$
y_{3, s p t}=\beta x_{s p t}+\zeta_{s}+u_{3, s p t}
$$

where $y_{3, s p t}$ is the average of value added in each sector-province-year, i.e., the left hand side of Equation 16, $x_{\text {spt }}$ is the average of labor in each sector-province-year adjusted by the estimate of $\widehat{w}_{s t}$ obtained from Equation 17, and $\zeta_{s}$ are sector fixed effects.

I back out parameters $\mu_{s p}, \sigma_{s p}, \Gamma_{p t}, w_{s t}$, and $f_{s}$ from the sector-province, province-time, sector-time, and sector fixed effects of Equations 17, 18, and 19, using their expressions in Equations 14, 15, and 16. For example, I derive $w_{s t}$ from the following equation:

$$
\widehat{\theta}_{s t}=\frac{\alpha}{(1-\alpha \gamma)}\left[\log (\alpha \gamma)-\log \left(w_{s t}\right)\right]
$$

where the left hand side $\widehat{\theta}_{s t}$ is estimated from Equation 17 and the right hand is the first component of the right hand side of Equation 14. I first assume specific values of $\alpha$ and $\gamma$ from the literature. ${ }^{22}$ Then, I derive sector-time specific wages from Equation 20:

$$
\widehat{w}_{s t}=\exp \left[\log (\alpha \gamma)-\frac{(1-\alpha \gamma)}{\alpha} \widehat{\theta}_{s p}\right]
$$

I follow the same reasoning to compute the other parameters.

\footnotetext{
${ }^{22}$ I follow Bartelsman et al. (2013), Bloom (2009), and Atkeson and Kehoe (2005) and assume a 20 percent markup that yields $\gamma$ equal to 0.83 , and that the decreasing return to scale parameter $\alpha$ is equal to 0.85 .
} 


\section{Second stage}

The second stage of the analysis focuses on the mafia-infiltrated markets. For each of these $N_{M}$ markets, I estimate the amount of pizzo that the mafia extorts from a randomly chosen group of firms, using the method of simulated moments (MSM). I let pizzo rate to decrease with firm's size and assume that $(\log )$ pizzo rate and firm's size have a linear relationship, whose slope is that estimated in Balletta and Lavezzi (2019) and whose intercept determines exactly how much every coerced firm in mafia-infiltrated markets has to transfer to the mafia. ${ }^{23}$ In particular, I estimate this intercept for each mafiainfiltrated sector, province, year, i.e. $\delta_{\text {spt }}$, and thus, in so doing, I am able to provide the first explicit estimate of pizzo extorted from firms located in Northern regions.

The set of parameters I compute in this stage is the vector $\Delta$, composed by the $N_{M}$ values of the intercept $\delta_{s p t}$ in each sector-province-year defined as infiltrated. Given that $\delta_{s p t}$ cannot be disentangled using aggregate data, it is not possible to estimate vector $\Delta$ using standard econometric techniques. The estimation of the parameters is instead achieved with the MSM, which minimizes a distance criterion between key moments from actual data and the corresponding moments computed using simulated data.

Specifically, for every sector-province-year, I generate a vector of firm-specific productivity $A_{i}$ from a log-normal distribution with average $\widehat{\mu}_{s p}$ and standard deviation $\widehat{\sigma}_{s p}$, estimated in the first stage. ${ }^{24}$ Firm-specific productivity is then multiplied by the previously computed province-year component $\widehat{\Gamma}_{p t}$. Next, I simulate distortions implied by the mafia. From the theoretical framework presented in Section 3. Recall that mafia impact is an idiosyncratic distortion that results from the interaction of the "mafia exposure" component $\tau_{i}$ with the "mafia intensity" component $\delta_{i}$. The "mafia exposure" component is assumed to follow a Bernoulli distribution with average $\lambda_{s p t}$. Hence, in each mafia-infiltrated market, $\lambda_{s p t}$ gives the share of firms that are impacted by the mafia. I construct $\lambda_{s p t}$ from actual data on reports of extortion in Northern Italy. ${ }^{25}$. Since

\footnotetext{
${ }^{23}$ Balletta and Lavezzi (2019) exploit a unique dataset on extortion in Sicily and estimate a slope parameter equal to -0.1 (see, for example, Figure 7 of their paper).

${ }^{24}$ The length of this vector is the observed number of firms that operate in the specific sector-provinceyear.

${ }^{25}$ The computation of $\lambda_{s p t}$ characterizing each impacted market is described in detail in Appendix A.3
} 
mafia targeting is not correlated to firms' productivity, I randomly select the share $\lambda_{s p t}$ of firms that, in each sector-province-year, must transfer pizzo, whose rate decrease with firm's size. Again, firm-specific pizzo rate is described by a line whose slope estimated in Balletta and Lavezzi (2019) and whose intercept $\delta_{\text {spt }}$ is the object of this stage of the estimation. Finally, I control for other types of mafia-infiltration by letting a certain group of firms to receive a direct transfer from mafia groups (Mirenda et al., 2019). ${ }^{26}$ Then, I simulate firms' labor, output, value added, and labor productivity according to the derivation presented in Section 3 and using the estimates of overhead labor $\widehat{f}_{s}$ and wage $\widehat{w}_{s t}$ obtained in the previous stage of the estimation. In practice, I feed my model with previously estimated parameters, necessary to control for the determinants of aggregate productivity that are unrelated to the mafia, and actual data on mafia activity, that is, information on direct transfers from mafia groups to firms measured in Mirenda et al. (2019), and information of pizzo racketeering, i.e., the average $\lambda_{s p t}$ of the distortion component $\tau_{i}$, in order to estimate the unobserved component of pizzo rate that the mafia imposes on firms, i.e., the component $\delta_{\text {spt }} .{ }^{27}$

I implement the MSM as follows: for each mafia infiltrated sector-province-year, I create a grid $\Theta$ of values that $\delta_{s p t}$ can take, and choose a set of observed data moments $\Phi^{O}$ that the model has to match. ${ }^{28}$ For each possible value of $\delta_{s p t}$ in $\Theta$, the model is solved and the simulated moments of interest $\Phi(\delta)^{S}$ are computed. The estimate of the vector containing the amount of pizzo imposed in each mafia-infiltrated market $\widehat{\delta}_{s p t}$ is derived according to the following criterion:

$$
\widehat{\delta}_{s p t}=\underset{\delta}{\arg \min }\left[\Phi^{O}-\Phi(\delta)^{S}\right]^{\prime} W\left[\Phi^{O}-\Phi(\delta)^{S}\right]
$$

\footnotetext{
${ }^{26}$ In particular, according to the aggregate statistics and information that L. Rizzica kindly provided me with, I let $0.9 \%$ of firms in each mafia-infiltrated market to receive a transfer equal to the $25 \%$ of their revenues. Among firms with revenues larger than the median revenue, I select the least productive ones.

${ }^{27}$ This approach speaks to the work of Ranasinghe and Restuccia (2018), who try to understand the role of crime and financial market development as sources of misallocation, using actual data on these frictions.

${ }^{28}$ The grid search method is useful for avoiding convergence problems with possible non-convexity or discontinuities of the objective function ( Equation 22).
} 
where $W$ is a weighting matrix. The procedure is iterated 2,000 times. ${ }^{29}$

I estimate an overidentified model, in which for each sector-province-year the set of moments to match includes: (i) the OP covariance between productivity and size, measured in terms of (log) labor productivity and employment share; (ii) average of (log) labor; (iii) and average (log) value added. The most important moment is the OP covariance between productivity and size. In fact, this analysis relies on the assumption that mafia extorting behavior generates factor misallocation. Thus, extortion acts perpetrated by the mafia can be seen as an extra determinant of allocative efficiency, which can be measured with the OP covariance. Controlling for any other factor that contributes to aggregate productivity that is unrelated to mafia, allows me to estimate $\delta_{s p t}$ as the parameter that minimizes distance between the simulated OP covariance and the observed one. The other two moments are included in order to estimate an overidentified model. The results obtained by estimating a just-identified model, i.e., by matching the OP covariance only, are congruent with those presented in this paper.

\section{Results}

This section presents the results obtained from the estimation strategy described in Section 5, where I first estimate the parameters of the model, which allows to control for any determinant of allocative efficiency that is unrelated to the mafia through fixed effects regressions on data on non-mafia markets. I then use these parameters together with actual data on the share of firms impacted by the mafia to apply the MSM. In particular, for each mafia-infiltrated market, I assume a linear relationship between (log) pizzo rate and firm's size, whose slope is estimated in (Balletta and Lavezzi, 2019), and I estimate its intercept $\widehat{\delta}_{s p t}$ by minimizing the distance between simulated OP covariance (measured in terms of (log) labor productivity and employment share over total mar-

\footnotetext{
${ }^{29}$ I estimate three versions of the model using three different weighting matrices: (i) the identity matrix, (ii) a weighting matrix that gives the OP covariance a weight that is twice that given to the other moment conditions, (iii) the optimal weighting matrix resulting from a two-stage estimation as in Hansen (1982). The results I present in this paper come from specification (i) and are comparable to those obtained in specifications (ii) and (iii). For a comprehensive description of the functioning of the MSM and its statistical properties see McFadden (1989).
} 
ket employment), (log) average labor, and ( $\log$ ) average value added, and the observed corresponding moments. This means that I am able to quantify pizzo as the only unobserved component of allocative efficiency of the infiltrated market, other things equal. More importantly, the structural approach adopted in this paper allows me to go beyond mere estimates of pizzo. I exploit these estimates and my model (Section 3) to understand the composition of the economic cost implied by extortion racketeering and to quantify it. Specifically, I first develop a simulation analysis where I show that the cost due to the mafia depends mainly on the output reduction for impacted firms. Next, I compute this economic loss through a counterfactual analysis that compares the aggregate value added of the infiltrated economy to the corresponding one without the mafia.

\subsection{Model estimation}

Estimates of pizzo are presented in Figure 4. In particular, this figure reports the estimates of average pizzo rate, imposed in each mafia-infiltrated sector s (with the 95\% confidence bands). The least impacted sectors are real estate activity and wholesale and retail trade, where average pizzo rate is $0.4 \%$. Construction and community, social, and personal services have the highest average pizzo, at $4.1 \%$ and $4.8 \%$ respectively . Finally, for the accommodation and food services sector the average tax is $1.7 \%$.

These results suggest that, on average, those firms located in mafia-infiltrated provinces that were extorted by organized crime in the years 2000-2012, lost between 0.4 and 5 percent of their output, depending on the sector. To the best of my knowledge, this is the first analysis to provide an explicit estimate of pizzo, expressed as a percentage of the output of the coerced firms located in Northern Italy.

\section{Accounting for other possible sources of misallocation}

The implicit assumption I make when quantifying pizzo is that all misallocation in the model is due to mafia infiltration. If public funds are inefficiently allocated across firms in mafia infiltrated industries (e.g., due to more entry or cronyism), then the estimates of pizzo presented above might also capture some of this misallocation and overstate the extent of extortion racketeering. Yet, several years after completion of the infras- 
Figure 4: Estimated average pizzo rate in each sector

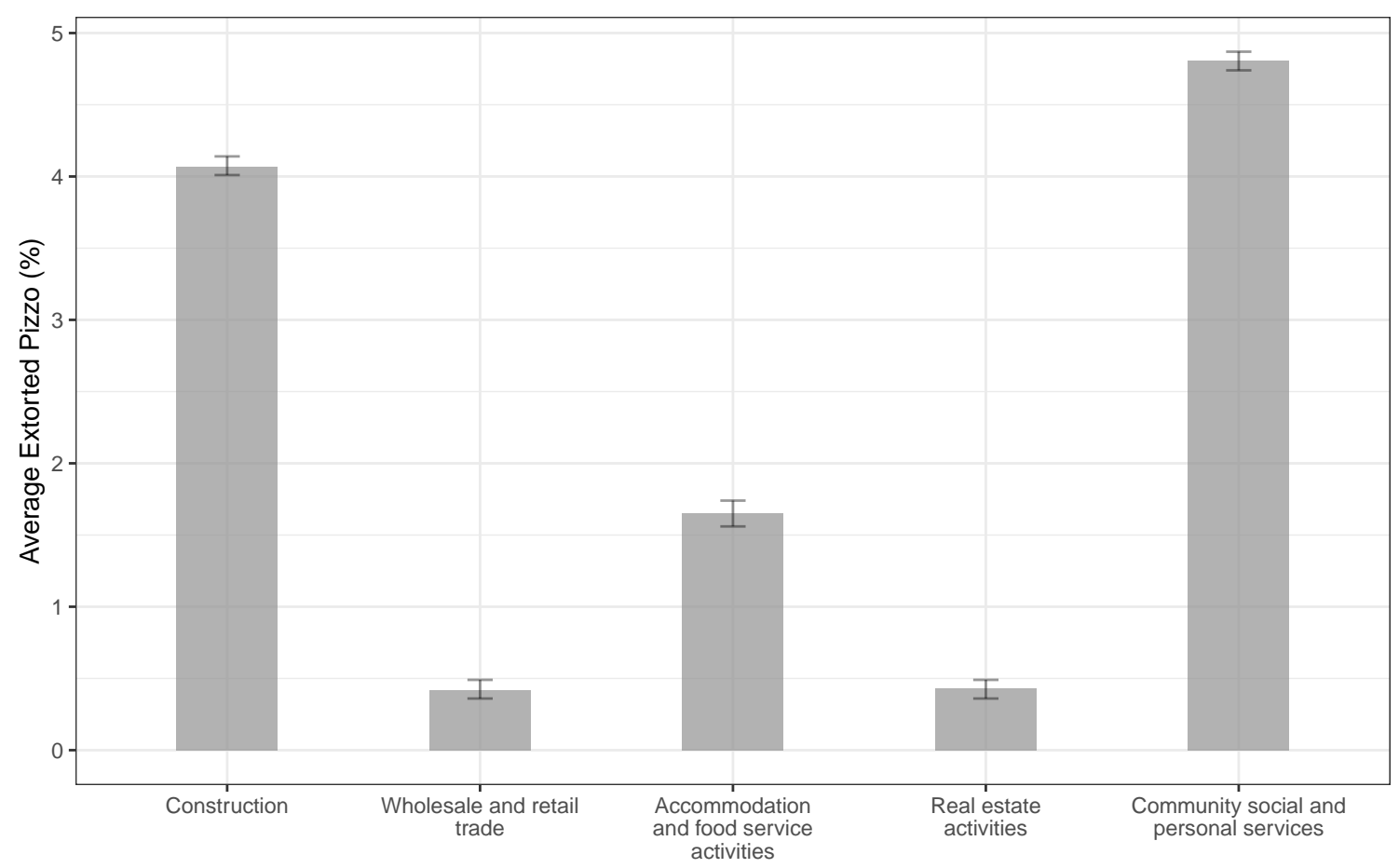

The estimates are obtained using aggregate data from the Small and Medium Entrepreneurs Survey available at the ISTAT-ADELE laboratory and information from the Annual Criminal Statistics Report by ISTAT. Results derived from the application of the Method of Simulated Moments (MSM) through a grid search. For every mafia infiltrated market the parameter to be estimated takes values from a grid bounded between 0 and 0.4. Within this grid, the chosen value is the one that minimizes the distance between simulated OP covariance, average (log) labor, and average (log) value added and the corresponding observed moments. The process was iterated 2,000 times. Each bar represents the average sectorial pizzo rate over the 2,000 iterations, together with their $95 \%$ confidence bands.

tructure projects, firms that have inefficiently benefited from public funds may shrink or exit, while extortion rates would be as observed in the data. Therefore, focusing on infiltrated markets several years after completion of the infrastructure projects may be a proper way to get unbiased estimates of pizzo, which would control for the potential "public funds effect" on misallocation.

I compute average sectorial extortion rate on a subsample of mafia-infiltrated markets. Specifically, the renewal works of the A4 highway and the Milan-Bologna high-speed rail have been completed between years 2007 and 2008. The only exception involves provinces located in Piedmont (i.e., Turin, Vercelli, Novara), where the projects have been completed in 2017. Since my data spans until 2012, I consider as period after completion of the rail-highway projects years 2010-2012 and I exclude the provinces located in Piedmont. 
Results are presented in Figure 5. The light-grey bars represent average pizzo rate (together with their 95\% confidence bands) displayed in Figure 4 and serve as baseline reference. The grey bars represent average pizzo rate computed on the provinces that I observe several years after completion of the high speed rail and highway projects during the whole mafia infiltration period, i.e. from year 2000 to 2012. Finally, the darkgrey bars represent average pizzo rate several years after completion of the infrastructure projects, i.e. in years 2010-2012. These findings suggest that estimates of average pizzo rate, while accounting for other possible sources of misallocation, do not change radically. This is true for wholesale and retail trade, accommodation and food service activities, real estate activity, and community social and personal services. In the latter sector, however, average pizzo rate computed in the subsample without Piedmont is larger than that estimated in the whole sample (average pizzo rate is approximately $6 \%$ instead of $5 \%$ ). The only exception concerns construction sector, where extortion rates drop significantly after completion of the infrastructure projects, i.e. in years 20102012. This suggest that, for this sector, a cleaner estimate of average extortion rate is approximately $2.7 \%$ instead of $4 \%$. Still, construction remains the second most heavily impacted sector, in terms of magnitude of pizzo rate. ${ }^{30}$

Finally, in Appendix A.4 I show that the number of firms did not increase in the infiltrated provinces, after the approval of the public funds for the renewal of the A4 highway and the Milan-Bologna high-speed rail. I also show in these provinces, after receiving funding for rail-highways, there are no differences in the change of the number of firms when comparing mafia and non-mafia sectors. This is a piece of evidence to support the idea that public funds did not lead to more entry and affect misallocation in provinces that received funding.

\footnotetext{
${ }^{30}$ In general, it is worth to recall that construction is the most sensitive sector in the analysis. Indeed, public funding for infrastructure is more likely to affect construction to a larger extent than other sectors.
} 
Figure 5: Amount of pizzo $\delta$ in mafia infiltrated sectors after completion of the projects

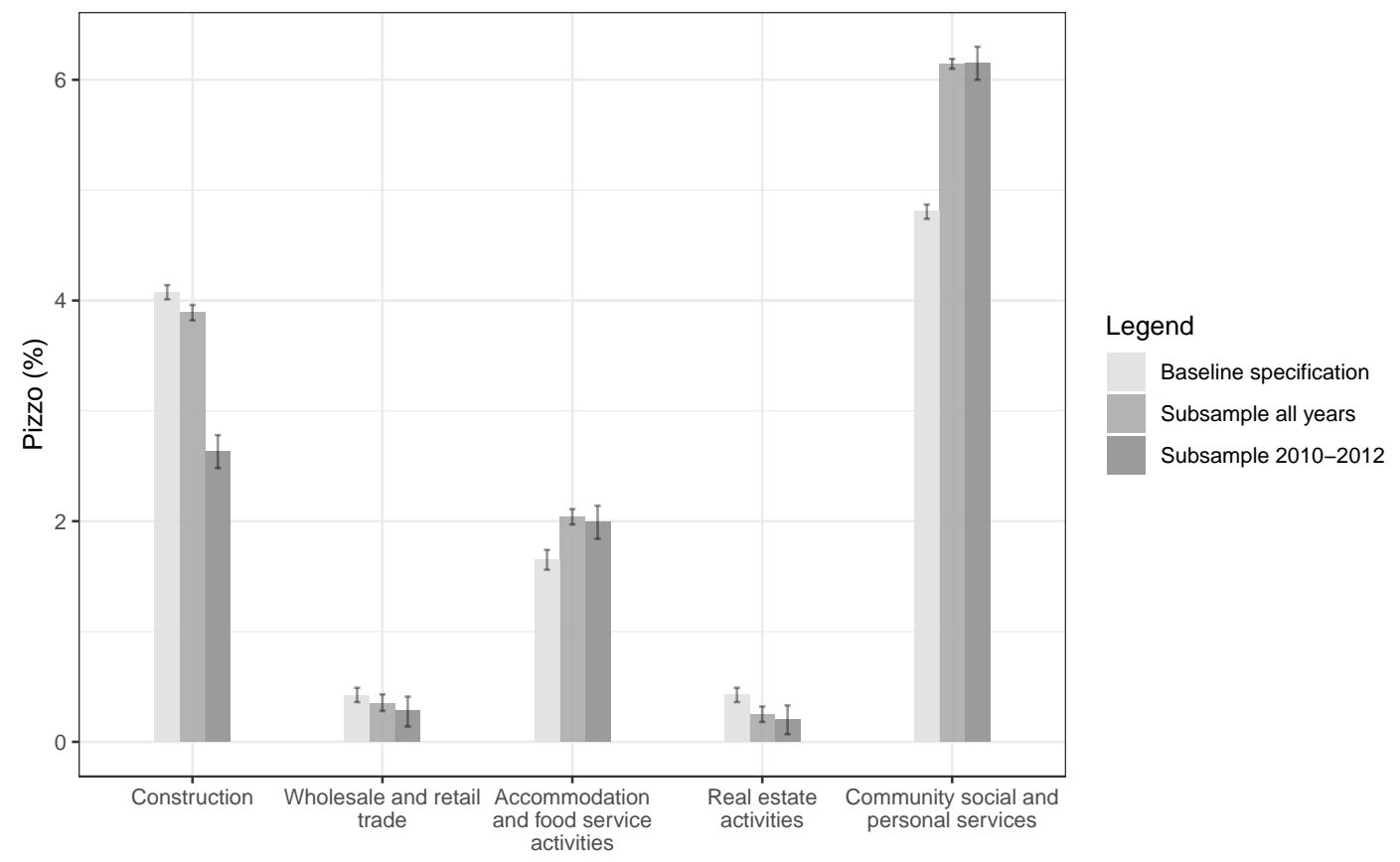

These estimates are obtained using aggregate data from the Small and Medium Entrepreneurs Survey available at the ISTAT-ADELE laboratory and information from the Annual Criminal Statistics Report published by ISTAT. The light-grey bars represent average pizzo displayed in Figure 4, as baseline reference. The grey bars represent average pizzo computed in the subsample of provinces that I observe several years after completion of the high speed rail and highway projects, i.e., excluding provinces located in Piedmont, during the whole time period of mafia infiltration. The dark-grey bars represent average pizzo computed in the subsample of provinces that I observe several years after completion of the infrastructures, during the years posterior to the completion of the projects (2010-2012).

\subsection{Unpacking the economic cost of the mafia}

In order to understand what exactly causes the economic loss due to mafia infiltration, I simulate the model of Section 3 to study how aggregate outcomes, such as market size and aggregate value added change, and how the aggregate transfer to the mafia and forgone production contribute to the total economic cost of extortion racketeering. I focus in particular on accommodation and food service activities, simulating a fictitious economy populated by 1,000 firms. ${ }^{31}$ To generate this market, I choose parameters obtained in the first stage of the estimation strategy developed in Section $5 .{ }^{32}$ Recall

\footnotetext{
${ }^{31}$ Results obtained simulating the other mafia-infiltrated sectors are reported in Appendix A.5.

${ }^{32}$ The mean and the standard deviation of TFP, and the sectorial wage are the median of the sectorial estimates $\widehat{\mu}_{s p}, \widehat{\sigma}_{s p}$, and $\hat{w}_{s t}$, where sector $s$ is accommodation and food services activities. Overhead labor
} 
that, as explained in Section 3, extortion racketeering generates an idiosyncratic distortion that can be expressed by the interaction of the "mafia exposure" component $\tau_{i}$ with the "mafia intensity" component $\delta_{i}$. The latter component is the rate of pizzo that a certain impacted firm has to pay. The former component is assumed to follow a Bernoulli distribution with average $\lambda$. Thus, $\lambda$ gives the share of firms that are impacted by the mafia. In this simulation, I fix $\delta_{i}=\delta$ equal to the average sectorial value of pizzo rate $(\delta=1.7 \%)$, and let the share of coerced firms vary between zero and one, i.e., $\lambda \in[0,1]$. Then, for each value of $\lambda$, I compute: (i) the total amount of pizzo transfered to the mafia (this component represents a waste of resources that would otherwise have been used productively); (ii) the total forgone value added of the firms that pay pizzo; and (iii) the forgone value added of the firms that leave the market. Each component is measured as the percentage of aggregate value added without the mafia, i.e., aggregate value added when $\lambda$ equals zero. Each simulation is iterated 25,000 times.

In practice, firm $i$ extracts its value of TFP, $A_{i}$, from a log-normal distribution, and operates if its expected profit is positive, where the expectation is based on the probability of facing extortion, i.e., $\lambda$. Conversely, if firm $i$ has negative expected profit it stays inactive. ${ }^{33}$ This fact has two main implications. First, aggregate value added decreases as $\lambda$ increases. In fact, if the share of firms subject to extortion increases, more and more firms will produce less. Second, given that mafia racketeering might imply firm exit, an increasing share of impacted firms might be followed by a reduction in market size, measured in terms of the number of active firms.

Figure 6 plots the results of this simulation. Specifically, the total loss is the sum of components (i), (ii), and (iii) described above. Clearly, this cost (thick blue line) increases with the share $\lambda$ of impacted firms. Quite remarkably, more than one half of this cost depends on forgone production. I present the exact shares of each component of the total loss in Section 6.3, where I describe a counterfactual analysis exercise in which

$\hat{f}_{s}$ is that obtained for the sector at hand. Finally, the province-year component of firms' productivity is the median value of the estimates $\widehat{\Gamma}_{p t}$.

${ }^{33}$ This assumption is motivated by the fact that, in the real world, if a firm is solicited by the mafia, it has to transfer pizzo or face retribution (La Spina et al., 2014). Therefore, for the coerced firm, it is optimal to continue producing in order to make the transfer, even if this means earning negative profits. 
firms of different sizes are extorted different pizzo rates. The estimation of the theoretical model developed in Section 3 thus provides a way not only to estimate the amount of pizzo extorted, but also to uncover the larger welfare cost in terms of lost production, which is more than two times higher than the mere transfer to the mafia. Moreover, firm inactivity is not a concern. This is compatible with what I observe in the data (see Appendix A.4).

Figure 6: The economic loss due to mafia

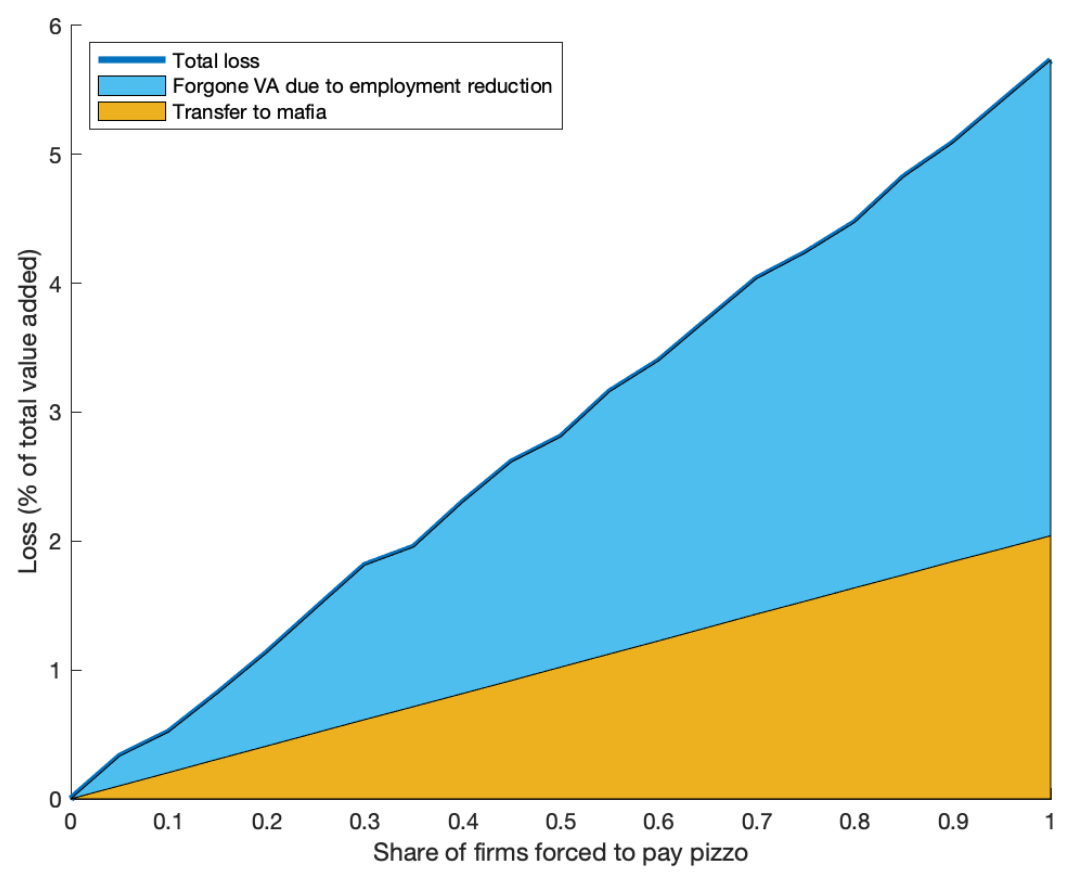

This figure depicts results from the simulation of the accommodation and food services sector. I set a common value of pizzo rate, i.e., $\delta$, to $1.7 \%$. This means that if a firm is subject to mafia racketeering, it must transfer $1.7 \%$ of its output. I let the share of impacted firms, i.e., $\lambda$, vary between zero and one. The yellow area shows how the loss implied by the transfer of pizzo changes as $\lambda$ increases. I add to this component the loss implied by forgone production due to output reduction implied by the fact that impacted firms hire less workers, i.e., the blue area. These components are expressed as the percentage of total value added without mafia infiltration. The total loss computed for each value of $\lambda$ is given by the thick blue line.

\subsection{Mafia, misallocation and output loss}

The previous subsection sheds light on the sources of the economic cost of extortion racketeering and the weight of each component. This loss depends mainly on the forgone production of firms subject to pizzo and, to a lesser extent, the actual transfer of 
protection money to the mafia. To provide an explicit estimate of the cost suffered by the Northern Italian economy, after mafia arrival, I implement a counterfactual analysis. Specifically, each mafia-infiltrated market is compared to its corresponding scenario without the mafia, i.e., where $\lambda$ is equal to zero. For each market, I compute the forgone value added of the impacted firms, which depends either on decrease in production or on firm exit, and the total amount of pizzo transferred to the mafia.

Table 1 reports the estimated aggregate loss of each mafia-infiltrated sector as a percentage of total sectoral value added. Quite remarkably, the share of the cost due to forgone value added is between the $75 \%$ and the $80 \%$ of the total loss. The most heavily impacted sectors are construction, and community, social, and personal services with an approximate total cost of $8.15 \%$ and $6.76 \%$ of aggregate sectoral value added respectively. These sectors are also those with the highest average values of pizzo (Figure 4). Meanwhile, the sectors with the lowest aggregate loss are those with the lowest average value of pizzo (Figure 4): wholesale and retail trade shows a total loss of $0.61 \%$, while that of the real estate activities sector is $0.71 \%$. Finally, accommodation and food services activities shows a total loss of $1.40 \%$. Approximately one-fourth of this cost consists of the mere transfer of pizzo to the mafia. The remaining three-fourths comprise the loss due to the reduction in production of infiltrated firms, a consequence of their need to pay pizzo. This is a key finding of the paper, as it calls attention to the fact that extortion racketeering entails a cost for the infiltrated economies, which is considerably higher than the resources that mafia groups collect. This result is robust to alternative specifications of the model, in which I relax the assumption that mafia targeting rule is not correlated with firm-specific productivity (see Section 7).

\section{Alternative specifications}

This section considers two extensions of the model presented in Section 3, in which I relax the assumption that the mafia impacts firms randomly and assume that their targeting negatively / positively correlates with firm-level productivity. On the one hand, according to Schelling (1971), it is more likely that, in a sector with heterogeneous firms, the less productive are infiltrated, as long as productivity is correlated to the availabil- 
Table 1: Aggregate loss due to the mafia (\% of aggregate sectorial value added)

Sector Forgone value added Transfer of pizzo Total loss

Construction

$6.53 \%$

$0.45 \%$

$1.62 \%$

$0.15 \%$

$1.07 \%$

$0.33 \%$

$0.53 \%$

$0.18 \%$

$5.42 \%$

$1.34 \%$

$8.15 \%$

$0.61 \%$

$1.40 \%$

$0.71 \%$

Community social and personal services

This table reports the average yearly aggregate economic loss, as a percentage of aggregate value added without the mafia. Column (1) reports the aggregate loss, as a percentage of aggregate value added, due to forgone value added. Column (2) reports the aggregate loss that accounts for the aggregate transfer to the mafia. Column (3) reports the aggregate total loss, i.e., the sum of columns (1) and (2).

ity of means that makes then more difficult to extort. On the other hand, the reverse scenario is also reasonable. Confesercenti (2012) provides anecdotal evidence that, in the transition from incursion to actual rooting, the mafia tries to target the wealthiest entrepreneurs (and coerces pizzo as one-off request).

In this exercise, the only deviation from the baseline model is the assumption relative to the relationship between mafia targeting and firm-level TFP. In this case, the probability that a firm is asked to pay pizzo must decrease / increase with its level of TFP. I model this aspect by building a distribution of mafia-related distortions that is negatively / positively correlated with firm i's draw of TFP, $A_{i}$. Therefore, firms can be ranked according to their individual probability of being extorted, and this probability is perfectly negatively / positively correlated with firm-level TFP. In each mafia-infiltrated market, firm $i$ 's maximization problem expressed in Equation 5 (Section 3) can be rewritten as:

$$
\Pi_{i}=\left(1-\zeta_{i} \delta_{i}\right) Y_{i} P_{i}-w_{s t} L_{i}
$$

Recall that mafia impact results from the interaction of two components: the "mafia exposure" component and the "mafia intensity" component, which gives the firm-specific amount of pizzo. What is modeled differently in this alternative specification is the "mafia exposure" component. This parameter, i.e., $\zeta_{i}$, follows a Bernoulli distribution, where the probability that $\zeta_{i}$ equals one decreases / increases with firm-level TFP, $A_{i}$ : 
$\frac{\partial \mathrm{P}\left(\zeta_{i}=1\right)}{\partial A_{i}}<0$ for negative correlation, and $\frac{\partial \mathrm{P}\left(\zeta_{i}=1\right)}{\partial A_{i}}>0$ for positive correlation. ${ }^{34}$ As in the baseline specification, "mafia intensity", i.e., $\delta_{i}$, is unobserved and is the object of the estimation.

For each infiltrated market, I estimate the amount of pizzo, extorted from a share $\lambda$ of firms, under the assumption that the mafia targets the least / most productive firms. To this end, I apply the second stage of the empirical strategy described in Section 5. Specifically, I implement the MSM and, in each mafia infiltrated market, pizzo is measured by minimizing the distance between simulated OP covariance (measured in terms of $(\log )$ labor productivity and employment share over total market employment), (log) average labor, and (log) average value added, and the observed corresponding moments. Findings are presented in Figure 7, where I report the estimates of average pizzo rate, imposed in each mafia-infiltrated sector $s$ (with the $95 \%$ confidence bands) assuming negative / positive correlation between firm-level productivity and probability of being coerced (light grey and dark grey respectively). First, the ranking of the magnitude of pizzo between sectors is the same as that obtained with the baseline specification (Figure 4). Second, the estimated average rates are higher with the targeting rule that uses negative correlation than those obtained assuming positive correlation. This results is compatible with the assumption presented in Sections 3 and 5 that firm-specific pizzo rate decreases with firm's size. Intuitively, firm-level TFP is proportional to firm-level size, therefore if less productive (and thus smaller) firms are more likely to be coerced by the mafia and smaller firms pays larger pizzo rates, the average pizzo rate will be larger than that estimated with the alternative targeting rule.

To measure the economic cost of extortion racketeering in this scenario, I perform the counterfactual analysis described in Section 6.3. Specifically, I simulate each infiltrated market with and without mafia activity, i.e., in the latter case $\lambda$ is set at zero. Then, for each market, I compute the total transfer to the mafia and the forgone value added due to both output reduction and firms' exit. Table 2 Panel A (Panel B) reports the results of the exercise that assumes negative (positive) correlation between firm-level produc-

\footnotetext{
${ }^{34}$ Details on how $\zeta_{i}$ is constructed in the two cases are provided in Appendix A.6.
} 
Figure 7: Amount of pizzo $\delta$ in mafia-infiltrated sectors

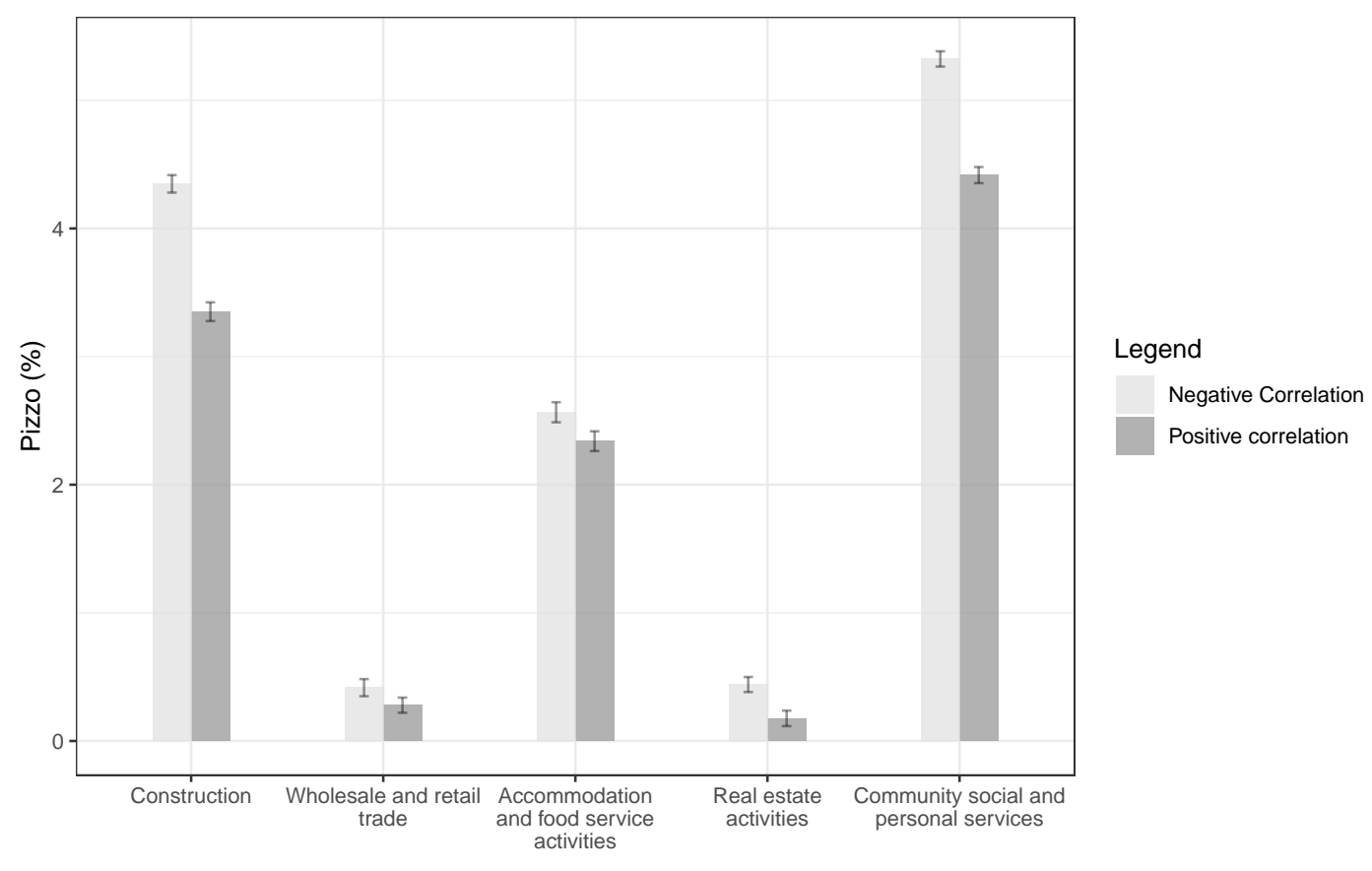

These estimates are obtained using aggregate data from the Small and Medium Entrepreneurs Survey available at the ISTAT-ADELE laboratory and information from the Annual Criminal Statistics Report published by ISTAT. Results derived from the application of the Method of Simulated Moments (MSM) through a grid search. For each mafia infiltrated market pizzo takes values from a grid bounded between 0 and 0.4. Within this grid, the chosen value is the one that minimizes the distance between simulated OP covariance, average (log) labor, and average (log) value added, and the corresponding observed moments. The process is iterated 2,000 times. Each bar represents the average sectoral pizzo rate over the 2,000 iterations, together with their 95\% confidence bands. The light gray bars are obtained assuming that firm-level productivity and probability of being coerced are negatively correlated. Conversely, the dark grey bars results from the exercise that assumes positive correlation.

tivity and firm-level size. In impacting firms in the upper tail of the TFP distribution, extortion racketeering reaches a sectoral aggregate loss that ranges between between $13.97 \%$ (for construction) and $0.44 \%$ (for wholesale and retail trade) of the aggregate value added in a scenario without mafia infiltration. Unsurprisingly, this cost is much higher than that computed in the exercise that assumes negative correlation and in the baseline model (Section 6.3). The only exception concerns wholesale and retail trade and real estate activities, the sectors with the lowest estimated average pizzo rate. More importantly, going beyond these estimate, it can be noticed that, for every sector, the composition of the loss is the same as that estimated in the baseline model. This means that, regardless the assumption made on the mafia targeting rule, the share of the cost given by output loss is three times larger than the size of the actual transfer to the mafia. Therefore, pizzo racketeering might entail a considerable cost for the coerced firms, even 
when mafia groups demand small transfers.

Table 2: Aggregate loss due to the mafia (\% of aggregate sectoral value added)

Panel A: Negative Correlation

Sector

Forgone value added Transfer of pizzo Total loss

Construction

Wholesale and retail trade

$4.02 \%$

$0.33 \%$

$0.99 \%$

$5.00 \%$

Accommodation and food service activities

$0.71 \%$

$0.11 \%$

$0.44 \%$

Real estate activities

$0.34 \%$

$0.20 \%$

$0.91 \%$

Community social and personal services

$3.59 \%$

$0.12 \%$

$0.46 \%$

$4.46 \%$

Panel B: Positive Correlation

Construction

Wholesale and retail trade

Accommodation and food service activities

Real estate activities

Community social and personal services

$\begin{array}{ccc}11.01 \% & 2.96 \% & 13.97 \% \\ 0.33 \% & 0.11 \% & 0.44 \% \\ 2.55 \% & 0.72 \% & 3.26 \% \\ 0.38 \% & 0.13 \% & 0.51 \% \\ 9.80 \% & 2.43 \% & 12.23 \%\end{array}$

This table reports the average yearly aggregate economic loss, as a percentage of aggregate value added without the mafia. Column (1) reports the aggregate loss, as a percentage of aggregate value added, due to forgone value added. Column (2) reports the aggregate loss that accounts for the aggregate transfer to the mafia. Column (3) reports the aggregate total loss, i.e., the sum of columns (1) and (2). Panel A reports the results of the model that assumes a negative correlation between firm-specific probability of being subject to extortion and firm-level productivity. Panel B reports the results of the model that assumes a positive correlation between firm-specific probability of being subject to extortion and firm-level productivity.

\section{Concluding remarks}

To shed greater light on the impact of illegal and underground economies, a better understanding of the link between micro idiosyncratic distortions and aggregate outcomes is crucial. Based on this idea, I develop a new methodology that allows to more accurately uncover the economic cost of such phenomena. In particular, I analyze how firms' response to pizzo racketeering impacts the allocation of resources in the infiltrated markets located in Northern Italy.

This paper is the first to estimate the amount of pizzo and to use these results to provide an explicit measure of the welfare loss due to extortion racketeering. Importantly, I show that the share of the cost given by output loss is three times larger than the size 
of the actual transfer to the mafia. This result suggests that pizzo racketeering implies a substantial cost even when the transfers imposed by organized crime are modest. My approach allows to uncover the actual size of the economic impact of extortion racketeering in Northern Italy.

While the mechanism I model may be context dependent, the empirical method to estimate it has general validity. It can, in fact, be applied to a wide range of contexts, as long as two indispensable pieces of information are available: (i) data on the extensive margin of the distortion, i.e., how many economic agents are involved; (ii) an instructive measure of the aggregate outcome that reflects the impact of the distortion of interest. Additionally, it is essential to make use of a robust counterfactual of how the studied framework would be without the hidden phenomenon. This is fundamental for controlling for any determinant of the studied aggregate outcome that is unrelated to the distortion of interest. Examples of new applications could include computing the economic cost of corruption in public procurement to firms, or assessing investment in the legal economy on the part of organized crime.

Extending my model to a general equilibrium perspective is a relevant application that I leave for future research. This will provide additional insights on the behavior of the economic agents behind illegal and underground economies, allowing to gain deeper knowledge of the hidden nature of such phenomena.

\section{References}

Acconcia, Antonio, Giancarlo Corsetti, and Saverio Simonelli, "Mafia and Public Spending: Evidence on the Fiscal Multiplier from a Quasi-experiment," American Economic Review, 2014, 104 (7), 2185-2209.

Amodio, Francesco and Michele Di Maio, "Making Do With What You Have: Conflict, Input Misallocation and Firm Performance," The Economic Journal, 2018, 128 (615).

Angelini, Paolo and Andrea Generale, "On the Evolution of Firm Size Distributions," American Economic Review, 2008, 98 (1). 
Atkeson, Andrew and Patrick J. Kehoe, "Modeling and Measuring Organization Capital," Journal of Political Economy, 2005, 113 (5), 1026-1053.

Balletta, Luigi and Mario Lavezzi, "The Economics of Extortion: Theory and Evidence on the SicilianMafia," Discussion Papers del Dipartimento di Economia e ManagementUniversità di Pisa, n.242, 2019.

Barone, Guglielmo and Gaia Narciso, “Organized crime and business subsidies: Where does the money go?," Journal of Urban Economics, 2015, 86 (C), 98-110.

Bartelsman, Eric, John Haltiwanger, and Stefano Scarpetta, "Cross-Country Differences in Productivity: The Role of Allocation and Selection," American Economic Review, 2013, 103 (1), 305-334.

Besley, Timothy and Hannes Mueller, "Predation, Protection, and Productivity: A Firm-Level Perspective," American Economic Journal: Macroeconomics, 2018, 10 (2).

Bloom, Nicholas, "The Impact of Uncertainty Shocks," Econometrica, 2009, 77 (3), 623685.

Buonanno, Paolo and Matteo Pazzona, "Migrating mafias," Regional Science and Urban Economics, 2014, 44 (C), 75-81.

_, Ruben Durante, Giovanni Prarolo, and Paolo Vanin, "Poor Institutions, Rich Mines: Resource Curse in the Origins of the Sicilian Mafia," The Economic Journal, 2015,125 (586).

Calderoni, Francesco and Stefano Caneppele, La geografia criminale degli appalti. Le infiltrazioni della criminalità organizzata negli appalti pubblici nel Sud Italia, Crime science, 2009.

Confesercenti, Le mani della criminalità sulle imprese: XIII rapporto di Sos Impresa, Aliberti Editore, 2012.

Daniele, Gianmarco and Gemma Dipoppa, "Doing Business Below the Line: Screening, Mafias and Public Funds," BAFFI CAREFIN Centre Research Paper No. 2018-98., BAFFI CAREFIN Centre 2019. 
Dipoppa, Gemma, "How Criminal Organizations Expand to Strong States: Migrant Exploitation and Political Brokerage in Northern Italy," APSA Preprints., 2021.

Donati, Cristiana and Domenico Sarno, "Are firms in "backward" areas of developed regions more financially constrained? The case of Italian SME's," Industrial and Corporate Change, 2015, 24 (6), 1353.

Galletta, Sergio, "Law enforcement, municipal budgets and spillover effects: Evidence from a quasi-experiment in Italy," Journal of Urban Economics, 2017, 101, 90 - 105.

Hansen, Lars Peter, "Large Sample Properties of Generalized Method of Moments Estimators," Econometrica, 1982, 50 (4), 1029-1054.

Hsieh, Chang-Tai and Peter J. Klenow, "Misallocation and Manufacturing TFP in China and India," The Quarterly Journal of Economics, 2009, 124 (4).

LeMoglie, Marco and Giuseppe Sorrenti, "Revealing "Mafia Inc."? Financial Crisis, Organized Crime, and the Birth of New Enterprises," The Review of Economics and Statistics, 06 2020, pp. 1-45.

McFadden, Daniel, "A Method of Simulated Moments for Estimation of Discrete Response Models Without Numerical Integration," Econometrica, 1989, 57 (5), 995-1026.

Mirenda, Litterio, Sauro Mocetti, and Lucia Rizzica, "The real effects of 'ndrangheta: firm-level evidence," Temi di discussione (Economic working papers), Bank of Italy, Economic Research and International Relations Area 2019.

Olley, G Steven and Ariel Pakes, "The Dynamics of Productivity in the Telecommunications Equipment Industry," Econometrica, 1996, 64 (6), 1263-97.

Piemontese, Lavinia, "The Spread of Mafia in Northern Italy: The Role of Public Infrastructure," Rivista di Politica Economica, 2013, (4), 113-140.

Pinotti, Paolo, "The Economic Costs of Organised Crime: Evidence from Southern Italy," The Economic Journal, 2015, 125 (586), 203-232.

Ranasinghe, Ashantha, "Property rights, extortion and the misallocation of talent," European Economic Review, 2017, 98 (C), 86-110. 
- and Diego Restuccia, "Financial frictions and the rule of law," Journal of Development Economics, 2018, 134, $248-271$.

Restuccia, Diego and Richard Rogerson, "Policy Distortions and Aggregate Productivity with Heterogeneous Plants," Review of Economic Dynamics, 2008, 11 (4), 707-720.

_ and _ , "Misallocation and productivity," Review of Economic Dynamics, 2013, 16 (1), $1-10$.

Schelling, Thomas C., "What Is the Business of Organized Crime?," The American Scholar, 1971, 40 (4), 643-652.

Scognamiglio, Annalisa, "When the mafia comes to town," European Journal of Political Economy, 2018, 55 (C), 573-590.

Skaperdas, Stergios, "The political economy of organized crime: providing protection when the state does not," Economics of Governance, November 2001, 2 (3), 173-202.

Spina, Antonio La, Giovanni Frazzica, Valentina Punzo, and Attilio Scaglione, "How Mafia Works: An Analysis of the Extortion Racket System," Technical Report 2014.

Transcrime, Progetto PON Sicurezza 2007-2013: Gli investimenti delle mafie. Rapporto Linea 1., Ministero dell'Interno, 2013.

Varese, Federico, Mafias on the Move: How Organized Crime Conquers New Territories, Princeton University Press, 2011. 


\section{A Appendix}

\section{A.1}

This appendix contains the proof of Proposition 1 introduced in Section 2.

Proposition 1 Consider the vector $\omega$ containing $N$ firm-level productivity ranked as follows $\omega_{1}>\omega_{2}>\omega_{3}>\ldots>\omega_{N}$. Consider the vector $\theta$ containing $N$ of firm-level size ranked as follows $\theta_{I}>\theta_{I I}>\theta_{I I I}>\ldots>\theta_{N}$.

If aggregate productivity is defined as the sum of firm-level productivity weighted by firm-level size, the way of maximising it is to have the ranking of firm-level productivity and firm-level size perfectly aligned. In other words, aggregate productivity is maximised when $\omega_{1}$ is matched to $\theta_{I}, \omega_{2}$ is matched to $\theta_{I I}$, and so forth. Proof. Consider two elements of $\omega, \omega_{1}>\omega_{2}$, and two elements of $\theta, \theta_{I}>\theta_{I I}$. To prove Proposition 1, Equation 1 must be true:

$$
\omega_{1} \theta_{I}+\omega_{2} \theta_{I I}>\omega_{1} \theta_{I I}+\omega_{2} \theta_{I}
$$

Given that $\omega_{1}>\omega_{2}, \omega_{1}$ can be written as follows: $\omega_{1}=\omega_{2}+\Delta \omega$ (with $\left.\Delta \omega>0\right)$. For the same reasoning $\theta_{I}=\theta_{I I}+\Delta \theta$ (with $\Delta \theta>0$ ). Plugging these expressions into Equation 1 and rearranging we obtain:

$$
\begin{gathered}
\left(\omega_{2}+\Delta \omega\right)\left(\theta_{I I}+\Delta \theta\right)+\omega_{2} \theta_{I I}>\left(\omega_{2}+\Delta \omega\right) \theta_{I I}+\omega_{2}\left(\theta_{I} I+\Delta \theta\right) \\
\omega_{2} \theta_{I I}+\Delta \omega \Delta \theta+\Delta \omega \theta_{I I}+\Delta \theta \omega_{2}+\omega_{2} \theta_{I I}>\omega_{2} \theta_{I I}+\Delta \omega \theta_{I I}+\omega_{2} \theta_{I I} \Delta \theta \omega_{2}
\end{gathered}
$$

That leads to:

$$
\Delta \omega \Delta \theta>0
$$

which is always true.

Pick two other elements from vector $\omega$ and vector $\theta$, such that $\omega_{A}>\omega_{B}$ and $\theta_{C}>\theta_{D}$. Given the computations provided above, we know that:

$$
\omega_{A} \theta_{C}+\omega_{B} \theta_{D}>\omega_{A} \theta_{D}+\omega_{B} \theta_{C}
$$


therefore:

$$
\omega_{1} \theta_{I}+\omega_{2} \theta_{I I}+\omega_{A} \theta_{C}+\omega_{B} \theta_{D}>\omega_{1} \theta_{I I}+\omega_{2} \theta_{I}+\omega_{A} \theta_{D}+\omega_{B} \theta_{C}
$$

We can apply this reasoning to every element of vector $\omega$ and vector $\theta$.

\section{A.2}

In what follows, I present a validation exercise of the definition of mafia-infiltrated market (Section 4). I show that, in provinces and years defined as mafia infiltrated, there was an increase in mafia activity, even if quantified with an alternative measure than Piemontese (2013). I measure it by the number of confiscations that occurred in each northern province, between the years 1993 and 2015. ${ }^{35}$ I implement a DD strategy to check whether there is an increase in average seizures in mafia-infiltrated provinces, after the approval of renewal works of the A4 highway and the Milan-Bologna high speed railway, relative to the other northern provinces. I estimate the following model:

$$
\text { Confiscation }_{p t}=\alpha+\gamma \times \text { Mafia }_{p t}+\theta_{t}+\theta_{r}+u_{p t}
$$

The left hand side variable is the number of confiscations that occurred in province $p$, at time $t$. The variable Mafia $p t$ is a dummy that equals one if province $p$ is mafia-infiltrated and $t$ indicates a year after the arrival of the mafia. Finally, $\theta_{t}$ and $\theta_{r}$ are year and region fixed effects. I use the latter in the baseline specification as the process of confiscation is carried out by the Anti-Mafia District Directorate (Direzione Distrettuale Antimafia, $D D A)$, which is a regional judicial body. ${ }^{36}$ I also implement other specifications of the model: (i) I include province fixed effects; (ii) I estimate a more demanding model that includes region-year and province fixed effects; (iii) I control for province-specific time trends to capture the possible presence of time-varying characteristics at the province level. Finally, given that the data shows that the number of seizures in the province of

\footnotetext{
${ }^{35}$ Data on confiscations from the mafia are provided by the ANBSC and are described in Section 4.

${ }^{36}$ To be precise, the $D D A$ is not officially a regional body, but in Northern Italy there is a DDA office located in each regional capital, with the exception of Aosta Valley, which shares the DDA with Piedmont.
} 
Milan is significantly higher than in any other province, I remove it from each specification in order to exclude the hypothesis that this province is driving the results.

The findings are presented in Table A1 and show that the coefficient of the variable Mafia $_{p t}$ is always positive and strongly significant in each specification, suggesting that on average, relative to non-mafia territories, mafia activity is higher in provinces defined as mafia-infiltrated, after mafia arrival. These results corroborate the hypothesis studied in Piemontese (2013) and, consequently, my definition of mafia-infiltrated market. 
Table A1: Mafia presence and confiscation of firms

\begin{tabular}{|c|c|c|c|c|c|c|c|c|}
\hline & $\begin{array}{c}(1) \\
\text { Seizures }\end{array}$ & $\begin{array}{c}(2) \\
\text { Seizures }\end{array}$ & $\begin{array}{c}(3) \\
\text { Seizures }\end{array}$ & $\begin{array}{c}(4) \\
\text { Seizures }\end{array}$ & $\begin{array}{c}(5) \\
\text { Seizures }\end{array}$ & $\begin{array}{c}(6) \\
\text { Seizures }\end{array}$ & $\begin{array}{c}(7) \\
\text { Seizures }\end{array}$ & $\begin{array}{c}(8) \\
\text { Seizures }\end{array}$ \\
\hline Mafia infiltrated province-year & $\begin{array}{c}1.527^{* * *} \\
(0.297)\end{array}$ & $\begin{array}{c}0.894^{* * *} \\
(0.216)\end{array}$ & $\begin{array}{c}1.027^{* * *} \\
(0.226)\end{array}$ & $\begin{array}{c}0.668^{* * *} \\
(0.185)\end{array}$ & $\begin{array}{c}1.194^{* * *} \\
(0.306)\end{array}$ & $\begin{array}{c}0.679 * * * \\
(0.251)\end{array}$ & $\begin{array}{c}2.513^{* * *} \\
(0.504)\end{array}$ & $\begin{array}{c}1.118^{* * *} \\
(0.359)\end{array}$ \\
\hline Observations & 1,155 & 1,051 & 1,155 & 1,051 & 1,155 & 1,051 & 1,155 & 1,051 \\
\hline R-squared & 0.316 & 0.285 & 0.570 & 0.492 & 0.691 & 0.679 & 0.659 & 0.616 \\
\hline Region FE & YES & YES & $\mathrm{NO}$ & $\mathrm{NO}$ & $\mathrm{NO}$ & NO & $\mathrm{NO}$ & $\mathrm{NO}$ \\
\hline Province FE & $\mathrm{NO}$ & $\mathrm{NO}$ & YES & YES & YES & YES & YES & YES \\
\hline Year FE & YES & YES & YES & YES & YES & YES & YES & YES \\
\hline Region-time FE & $\mathrm{NO}$ & $\mathrm{NO}$ & $\mathrm{NO}$ & $\mathrm{NO}$ & YES & YES & $\mathrm{NO}$ & $\mathrm{NO}$ \\
\hline Province Time Trend & $\mathrm{NO}$ & $\mathrm{NO}$ & $\mathrm{NO}$ & $\mathrm{NO}$ & $\mathrm{NO}$ & $\mathrm{NO}$ & YES & YES \\
\hline Exclude Milan & $\mathrm{NO}$ & YES & $\mathrm{NO}$ & YES & $\mathrm{NO}$ & YES & $\mathrm{NO}$ & YES \\
\hline
\end{tabular}

Source: Computations based on ANBSC data on firms seized from the mafia. Robust standard errors in parentheses. ${ }^{* * *} \mathrm{p}<0.01,{ }^{* *} \mathrm{p}<0.05,{ }^{*}$ $\mathrm{p}<0.1$. The dependent variable in columns (1)-(8) is the number of confiscations of firms that occurred in province $p$ at time $t$. Variable "Mafia province after mafia arrival" is a dummy that equals one if province $p$ is defined as mafia infiltrated and time $t$ is a year posterior to mafia arrival. Columns (1) and (2) include region and year fixed effects; the latter excludes the province of Milan from the sample. Columns (3) and (4) include province and year fixed effects, the latter again excludes the province of Milan from the sample. Columns (5) and (6) control for region-time fixed effects; the latter excludes the province of Milan from the sample. Columns (7) and (8) include province-specific time trends, the latter excludes the province of Milan from the sample. 


\section{A.3}

In this appendix I describe in detail how I construct the share of firms subject to extortion racketing in each mafia infiltrated market, $\lambda_{p t}$. This variable must be zero in markets that are not defined as mafia-infiltrated. Therefore, for each mafia province, I tailor yearly reports of extortion in a difference-in-differences fashion. In particular, I compute $\lambda_{p t}$ as the increase in reports of extortion registered in the infiltrated provinces after mafia arrival. To this end, I adjust the number of extortion cases observed in every mafia-infiltrated province-year as follows:

$$
\tilde{e}_{p t}=\text { mafia province year }{ }_{p t} \times\left[\left(e_{p t}-\bar{e}_{p, P R E}\right)-\left(\bar{e}_{-p t}-\bar{e}_{-p, P R E}\right)\right]
$$

where $\tilde{e}_{p t}$ is the adjusted number of extortion cases, mafia province year ${ }_{p t}$ is a dummy that equals one if the province-year is infiltrated, $e_{p t}$ is the number of extortion cases observed in the raw data, $\bar{e}_{p, P R E}$ and $\bar{e}_{-p, P R E}$ are the averages of reports of extortion from 1998 until the year of the infrastructure renewal approval in mafia provinces and non-mafia provinces, respectively, and $\bar{e}_{-p t}$ is the yearly average for every mafia-year of the number of extortion cases observed in non-mafia provinces. ${ }^{37}$ Then, I compute the share of impacted firms as follows:

$$
\lambda_{p t}=\max \left[\frac{\tilde{e}_{p t}}{N_{p t}}, 0\right]
$$

where $N_{p t}$ is the number of firms operating in province $p$ at time $t$.

This measure of the share of firms impacted in every mafia province-year uses the number of reports of extortion observed in the specific province-year, adjusted by the difference in the average extortion cases between mafia and non-mafia provinces from 1998 until the year of renewal work approval, and adjusted by the average extortion cases in the non-mafia provinces after mafia arrival. If this value is lower than zero, I replace it

\footnotetext{
${ }^{37}$ Note that some mafia-infiltrated provinces start to be infiltrated in 2000 . For these provinces, $\bar{e}_{p, P R E}$ and $\bar{e}_{-p, P R E}$ are computed between the years 1998 and 2000. For the remaining mafia-infiltrated provinces, $\bar{e}_{p, P R E}$ and $\bar{e}_{-p, P R E}$ are computed between 1998 and 2002.
} 
with zero and exclude that specific province-year from the analysis. This results in the exclusion of two mafia-infiltrated provinces from the analysis. ${ }^{38}$

\section{A.4}

In what follows, I explore whether the number of firms changed in mafia-markets, after receiving funding for infrastructures (A4 motorway and the Milan-Bologna high speed rail). Specifically, I perform the following triple difference-in-differences:

Number of firms $s_{s p t}=\alpha+\theta$ Mafia-market $_{s p t}+\gamma_{1} x_{1 s t}+\gamma_{2} x_{2 p t}+\gamma_{3} x_{3 s p}+\eta_{s}+\eta_{p}+\eta_{t}+u_{s p t}$

The dependent variable is the number of firms observed in a given sector $s$, province

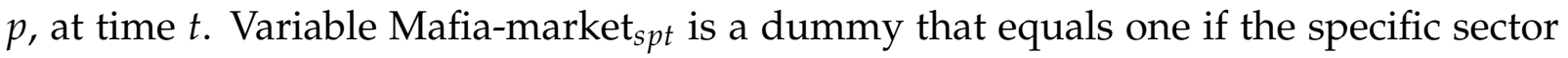
$s$, in province $p$, at time $t$ is mafia-infiltrated, according to the definition presented in Section 4. $x_{1 s t}, x_{2 p t}$, and $x_{3 s p}$ are interaction terms between the dummies that defines mafia sectors, mafia provinces, and mafia years, i.e., $x_{1 s t}$ equals one if sector $s$ and year $t$ are mafia-infiltrated, $x_{2 p t}$ equals one if province $p$ and year $t$ are mafia-infiltrated, $x_{3 s p}$ equals one if sector $s$ and province $p$ are mafia-infiltrated. The model includes sector, province, and year fixed effects (column (1) Table A2). In a second specification I include region-time fixed effects (column (2) Table A2). Finally, I perform a more demanding model where $x_{1 s p t}, x_{2 s p t}$, and $x_{3 s p t}$ and the fixed effects are replaced by sector-province, province-time, and sector-time fixed effects (column (3) Table A2).

Results are reported in Table A2. The three specifications do not show any significant correlation between mafia presence and firm entry. In particular, the number of firms does not increase in mafia infiltrated compared to non-mafia sectors in provinces that received funding for infrastructures. Moreover, the change in number of firms in provinces that received funding is not stronger than that characterizing the non-mafia provinces.

\footnotetext{
${ }^{38}$ Given that I don't have information on the sectorial intensity of extortion, I assume that the mafia evenly impacts every sector. Thus, in order to obtain the sectorial share of firms that is impacted $\left(\lambda_{s p t}\right), \mathrm{I}$ divide $\lambda_{p t}$ by five, i.e., the number of sectors defined as mafia infiltrated.
} 
Table A2: Public funds and firm entry

(1)

(2)

(3)

Number of firms Number of firms Number of firms

\begin{tabular}{|c|c|c|c|}
\hline Mafia infiltrated market & $\begin{array}{c}1.918 \\
(6.386)\end{array}$ & $\begin{array}{c}1.639 \\
(6.466)\end{array}$ & $\begin{array}{l}-9.576 \\
(7.624)\end{array}$ \\
\hline Mafia infiltrated sector-year & $\begin{array}{c}6.436 \\
(3.935)\end{array}$ & $\begin{array}{c}6.696 \\
(4.022)\end{array}$ & \\
\hline Mafia infiltrated province-year & $\begin{array}{c}-3.992^{* *} \\
(1.839)\end{array}$ & $\begin{array}{c}2.179 \\
(1.937)\end{array}$ & \\
\hline Mafia infiltrated sector-province & $\begin{array}{c}16.009 \\
(19.046)\end{array}$ & $\begin{array}{c}16.262 \\
(19.183)\end{array}$ & \\
\hline Observations & 9,081 & 9,081 & 9,081 \\
\hline R-squared & 0.485 & 0.498 & 0.839 \\
\hline Province FE & YES & YES & NO \\
\hline Year FE & YES & $\mathrm{NO}$ & NO \\
\hline Sector FE & YES & YES & $\mathrm{NO}$ \\
\hline Region-Year FE & $\mathrm{NO}$ & YES & NO \\
\hline Province-Sector FE & $\mathrm{NO}$ & $\mathrm{NO}$ & YES \\
\hline Province-Time FE & $\mathrm{NO}$ & $\mathrm{NO}$ & YES \\
\hline Sector-Time FE & $\mathrm{NO}$ & $\mathrm{NO}$ & YES \\
\hline $\begin{array}{l}\text { ource: Computations based on SME Su } \\
\text { 0.1. The dependent variable in colum } \\
\text { Mafia-infiltrated market is a dummy } t \\
\text { rival. Mafia sector-year is a dummy th } \\
\text { ovince-year is a dummy that equals o } \\
\text { ovince is a dummy that equals one if se }\end{array}$ & bust s & par & $\begin{array}{l}01, * * \\
\text { vince } \\
\text { nce, a } \\
\text { filtrat } \\
\text {. Ma }\end{array}$ \\
\hline
\end{tabular}

\section{A.5}

In this Appendix, I report the results of the simulation exercise presented in Section 6.2 performed on the remaining mafia-infiltrated sectors, i.e., construction (top-left panel), wholesale and retail trade (top-right panel), real estate activities (bottom-left panel), community, social, and personal services (bottom-right panel). 


\section{Figure A5: The economic loss due to mafia}
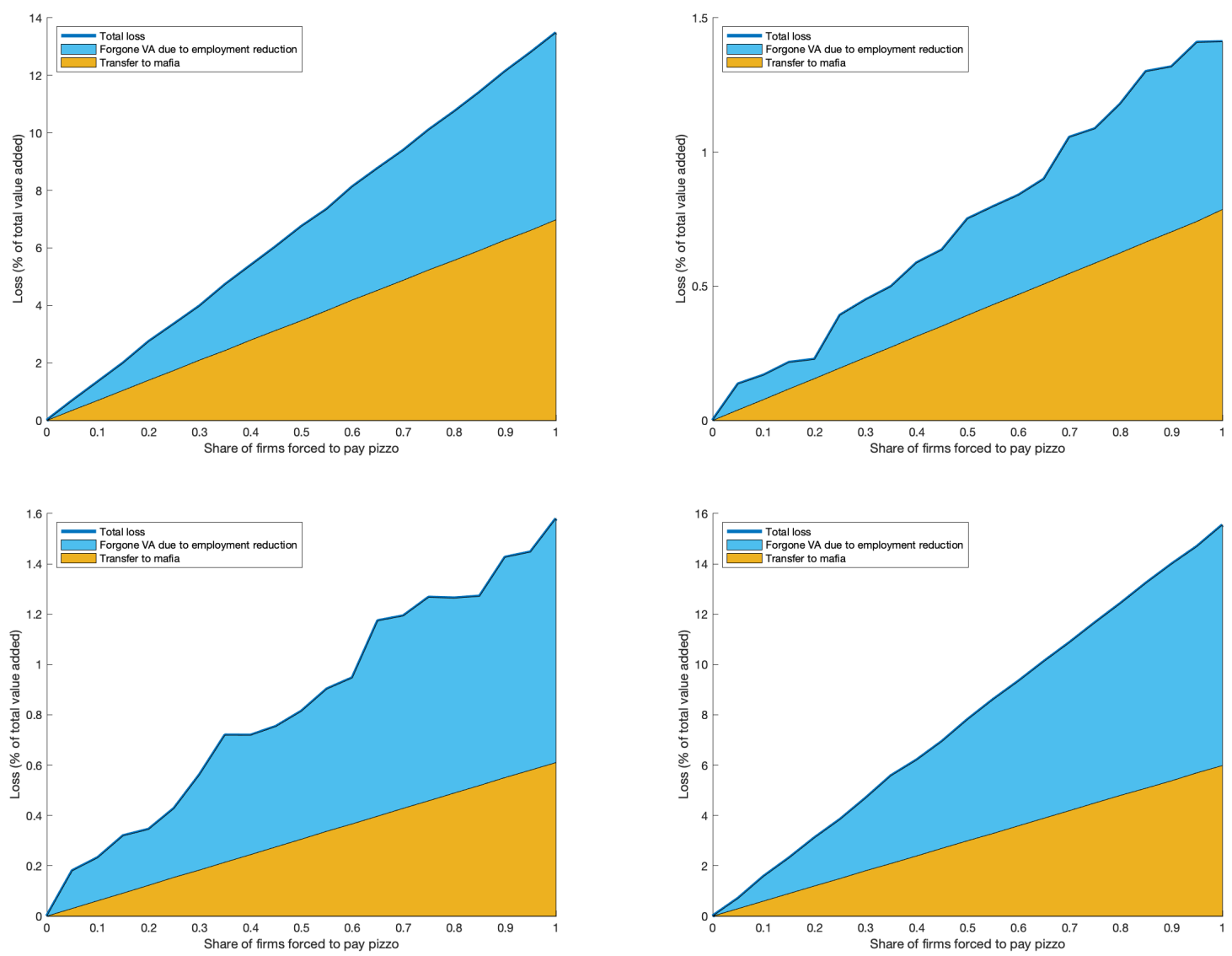

This figure depicts results from the simulation of mafia-infiltrated sectors. I set the value of pizzo, i.e., $\delta$, to the estimate reported in Figure 4 and I let the share of impacted firms, i.e., $\lambda$, vary between zero and one. The yellow area shows how the loss implied by the transfer of pizzo changes as $\lambda$ increases. I add to this component the loss implied by forgone production due to output reduction implied by the fact that impacted firms hire less workers, i.e., the blue area. These components are expressed as the percentage of total value added without mafia infiltration. The total loss computed for each value of $\lambda$ is given by the thick blue line. 


\section{A.6}

This appendix shows how the construction of a negative / positive relationship between mafia targeting and firm-level TFP. Recall that mafia impact results from the interaction of: "mafia exposure" component and "mafia intensity" component. The former parameter, $\zeta_{i}$ follows a Bernoulli distribution, where the probability that $\zeta_{i}$ equals

one increases with firm-level TFP, $A_{i}$, i.e. $\frac{\partial \mathrm{P}\left(\zeta_{i}=1\right)}{\partial A_{i}}<0$ with negative correlation, and $\frac{\partial \mathrm{P}\left(\zeta_{i}=1\right)}{\partial A_{i}}>0$ with positive correlation.

Figure A7 plots the relationship between $\mathrm{P}\left(\zeta_{i}=1\right)$ and $A_{i} \cdot{ }^{39}$ This relationship can be described by the following curves:

$$
\mathrm{P}\left(\zeta_{i}=1\right)=\frac{1}{(\bar{A}-\underline{A})^{2}} A_{i}^{2}-\frac{2 \bar{A}}{(\bar{A}-\underline{A})^{2}} A_{i}+\frac{\bar{A}^{2}}{(\bar{A}-\underline{A})^{2}}
$$

for negative correlation;

$$
\mathrm{P}\left(\zeta_{i}=1\right)=-\frac{1}{(\bar{A}-\underline{A})^{2}} A_{i}^{2}+\frac{2 \bar{A}}{(\bar{A}-\underline{A})^{2}} A_{i}+1-\frac{\bar{A}^{2}}{(\bar{A}-\underline{A})^{2}}
$$

for positive correlation.

In both cases, $\bar{A}$ and $\underline{A}$ are the maximum and the minimum value of $A_{i}$ respectively. This means that the least / most productive firm in terms of TFP is subject to mafia extortion with probability one, and the most / least productive firm is exposed with probability zero. Then, according to its own realization of $\zeta_{i}$, firm $i$ is impacted by the mafia or not. If the share of firms with $\zeta_{i}=1$ exceeds the observed share of firms extorted by mafia, $\lambda$, a subsample of firms is randomly drawn from those firms with $\zeta_{i}=1$, such that the share of impacted firms is exactly $\lambda$.

\footnotetext{
${ }^{39}$ I plot, as example, results obtained from one specific mafia-infiltrated market.
} 
Figure A7: Mafia targeting negatively/positively correlated with firm-level TFP
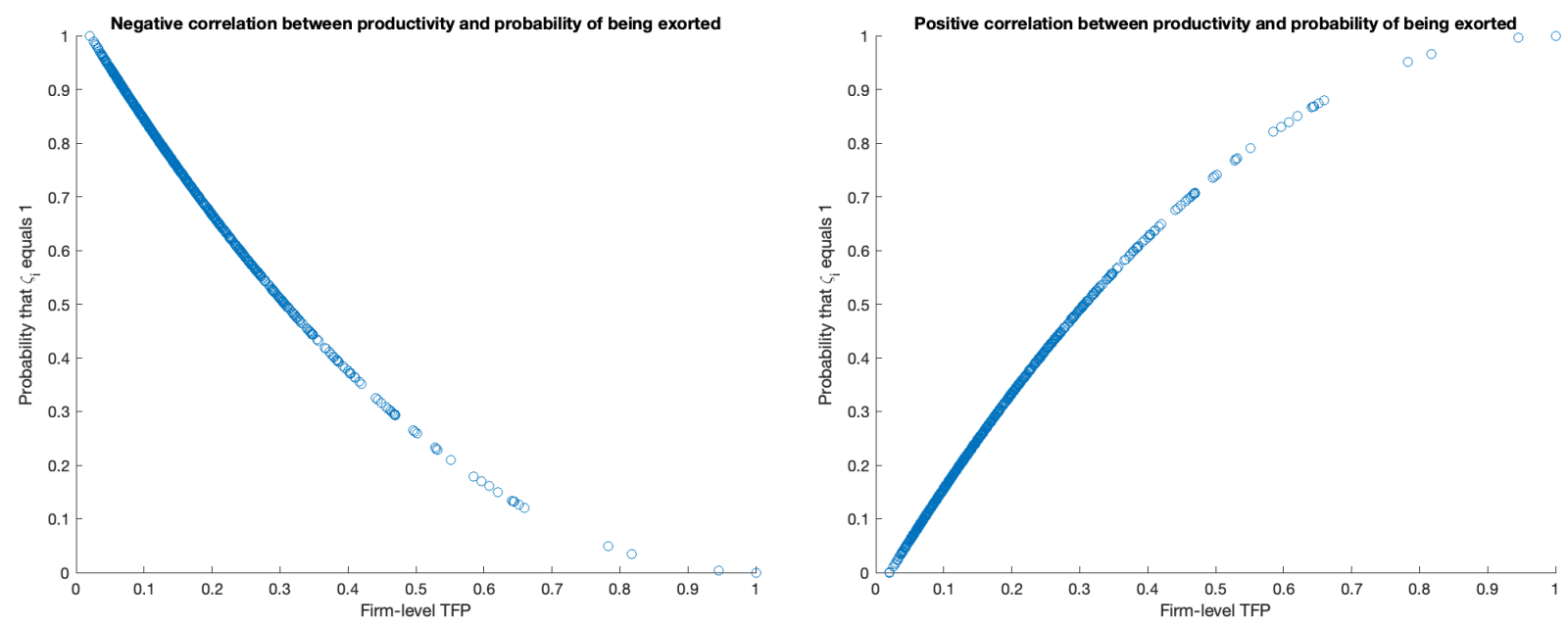

This figure plots the non-linear relationship between firm-level TFP and the probability of being impacted by the mafia. Left panel: the correlation between probability of being coerced and TFP is negative. This relationship can be described by a curve with the following equation: $\mathrm{P}\left(\zeta_{i}=1\right)=$ $\frac{1}{(\bar{A}-\underline{A})^{2}} A_{i}^{2}-\frac{2 \bar{A}}{(\bar{A}-\underline{A})^{2}} A_{i}+\frac{\bar{A}^{2}}{(\bar{A}-\underline{A})^{2}}$. Right panel: the correlation between probability of being coerced and TFP is positive. This relationship can be described by a curve with the following equation: $\mathrm{P}\left(\zeta_{i}=1\right)=$ $-\frac{1}{(\bar{A}-\underline{A})^{2}} A_{i}^{2}+\frac{2 \bar{A}}{(\bar{A}-\underline{A})^{2}} A_{i}+1-\frac{\bar{A}^{2}}{(\bar{A}-\underline{A})^{2}}$. In both cases, $\bar{A}$ and $\underline{A}$ are the maximum and the minimum value of $A_{i}$ respectively. 